\title{
Estimation of Turbulence Level and Scale for Wind Turbine Applications
}

D. C. Powell

November 1988

Prepared for

the U.S. Department of Energy

under Contract DE-AC06-76RLO 1830

Pacific Northwest Laboratory

Operated for the U.S. Department of Energy

by Battelle Memorial Institute 


\title{
DISCLAIMER
}

This report was prepared as an account of work sponsored by an agency of the United States Government. Neither the United States Government nor any agency thereof, nor Battelle Memorial Institute, nor any or their employees, makes any warranty, expressed or implied, or assumes any legal liability or responsibility for the accuracy, completeness, or usefulness of any information, apparatus, product, or process disclosed, or represents that its use would not infringe privately owned rights. Reference herein to any specific commercial product, process, or service by trade name, trademark, manufacturer, or otherwise does not necessarily constitute or imply its endorsement, recommendation, or favoring by the United States Government or any agency thereof, or Battelle Memorial Institute. The views and opinions of authors expressed herein do not necessarily state or reflect those of the United States Government or any agency thereof.

\author{
PACIFIC NORTHWEST LABORATORY \\ operated by \\ BATTELLE MEMORIAL INSTITUTE \\ for the \\ UNITED STATES DEPARTMENT OF ENERGY \\ under Contract DE-AC06-76RLO 1830
}

\author{
Printed in the United States of America \\ Available from \\ National Technical information Service \\ United States Department of Commerce \\ 5285 Port Royal Road \\ Springfieid, Virginia 22161 \\ NTIS Price Codes \\ Microfiche A01 \\ Printed Copy
}

$\begin{array}{cc}\text { Pages } & \begin{array}{c}\text { Price } \\ \text { Codes } \\ 001-025\end{array} \\ 026-050 & \text { A02 } \\ 051-075 & \text { A03 } \\ 076-100 & \text { A04 } \\ 101-125 & \text { A05 } \\ 126-150 & \text { A06 } \\ 151-175 & \text { A07 } \\ 176-200 & \text { A08 } \\ 201-225 & \text { A09 } \\ 226-250 & \text { A10 } \\ 251-275 & \text { A11 } \\ 276-300 & \text { A12 } \\ & \text { A13 }\end{array}$


ESTIMATION OF TURBULENCE LEVEL AND

SCALE FOR WIND TURBINE APPLICATIONS

D. C. Powell

November 1988

Prepared for

the U.S. Department of Energy

under Contract DE-ACO6-76RLO 1830

Pacific Northwest Laboratory

Richland, Washington 993522 
.

" 


\section{ABSTRACT}

A simplified method is presented for estimating onsite turbulence variance within the wind turbine layer for horizontal wind speed. The method is based principally on estimating the probability distribution of wind speed and assigning a variance to each mean wind speed based on surface roughness estimates. The model is not proposed as an alternative to onsite measurement and analysis, but rather as an adjunct to such a program.

A revision of the Kaimal neutral u-component spectrum is suggested to apply to the mix of the stabilities occurring during operational winds.

Values of integral length scale calculated from data analysis are shown to contradict the length scale model implicit in turbulence power spectra. Also, these calculated values are shown to be extremely sensitive to the length of the time series and the detrending method used.

The analysis and modeling are extended to the rotational frame of reference for a horizontal-axis wind turbine by modeling the ratios of harmonic spike variances (1P, 2P, etc.) in the rotational spectrum to the Eulerian turbulence variance. 
. 


\section{SUMMARY}

The objective of this report is to provide pertinent information for estimating turbulence variance and scale as these parameters apply to wind turbine operations. All models recommended can be derived theoretically from models for the u component of turbulence. This is the alongwind component. For wind blowing fast enough to operate wind turbines, the u component is taken to be statistically equivalent to horizontal wind speed. The stochastic wind models that exist are based on the power spectral density of the u component. This report suggests, but with strong qualifications, models for the variance and for the integral length scales of u-component turbulence. Estimation problems of the two parameters are sufficientiy different that they are treated separately from this point on.

\section{ESTIMATION OF EULERIAN VARIANCE}

Although we suggest models for the Eulerian variance of $u$, we believe that estimation of Eulerian variance, as a contributor to fatigue, requires a measurement program operating long enough and over a sufficient variety of wind conditions to produce a probability distribution of variance. The period for measuring variance should be standardized to something like $15 \mathrm{~min}$, and the wind speed data used should be linearly detrended.

The measurement program should also produce concomitant values of mean wind speed for two reasons. First, an estimate of the power-producing resource is produced thereby. Second, variance and the square of mean wind speed may be associated empirically by such measurements, and this must be done if the results are going to checked by reference to any theoretical model.

Onsite turbulence variance may also be estimated by use of theoretical models. This report recommends those models considered optimum in a context of wind engineering and farming. However, such models require estimations of input that may be unreliable. Therefore estimation of onsite turbulence variance by theoretical modeling is perhaps dispensable, while estimation by measurement over a standardized period is indispensible.

The model of turbulence variance recommended in this report for a given value of mean wind speed requires the height of the wind speed and a surface 
roughness length. The surface roughness length must be estimated from a table, such as Table 2.1. This is because the required surface roughness length, while proportional to the size of features at the surface, is not the measure of any of these features individually. This is the estimate, which may not be reliable, as any investigator can see from inspecting the table, since it describes only a limited number of "text-book" surface types.

If the site obviously has different surface characteristics in different upwind directions, then there are as many individual problems of estimation as there are sectors to which different surface roughness lengths can be assigned. Results for each sector must be weighted according to the probability the wind will blow from each sector.

Only neutral stability (atmospheric stability) is modeled. By analyzing actual wind speed data taken in the field during a range of stability conditions and comparing observed with predicted results, we find that the results from the neutral model need to be upwardly corrected by about $30 \%$ to model variance in the observed data. This bias is probably the result of using the neutral stability model to model data taken at different stabilities. The other effect on variance in these data is that of stability variation. Within the spread of variance that is already caused by a range of mean wind values, the stability variation contributes another spread that we can ignore, particularly since stability variation is less important at high mean wind speeds.

Our final model of variance turns out to be

$$
\sigma_{\mathrm{u}}^{2}=1.2\left[\overline{\mathrm{U}}(\mathrm{H}) / \ln \left(\mathrm{H} / \mathrm{z}_{0}\right)\right]^{2}
$$

where $H$ is hub-height, $\bar{U}(H)$ is mean wind at $H$, and $z_{0}$ is surface roughness length. If the investigator has more confidence in his choice of $z 0$ than in his means of obtaining calculated variances based on measurement, then the equation may be used as a check on these means. Note that this model tells nothing about the probable level of variance. All it gives is estimation of variance for a given specification of mean wind speed and roughness.

At micrometeorological sites, $z_{0}$ is estimated by applying curve-fitting techniques of average wind speed data taken simultaneously at several heights on one tower when atmospheric stability is neutral. But when there is a choice 
of heights, the calculated value of $z_{0}$ from such analyses may differ significantly depending on which heights were chosen.

\section{ESTIMATION OF TURBULENCE LENGTH SCALE}

The integral scale of turbulence is in general a weak parameter for the following reasons. First of all, its values are more sensitive to changes in data handling than are other parameters of turbulence, such as variance. Secondly, there is considerable difference in the behavior of length scale as is predicted, explicitly or implicitly, by a spectral model of turbulence and that observed. However, for those applications that must have some simple input, we offer, subject to the considerable qualifications in Section 3, for the longitudinal and lateral integral length scales defined in Sections 1 and 3:

$$
\begin{aligned}
& L_{u x}=4.6 \mathrm{H} \\
& L_{u y}=1.8 \mathrm{H} .
\end{aligned}
$$

Equation (S.2) is shown to be consistent with state-of-the-art spectral models of turbulence, but inconsistent with the results of data analysis. However, for a hub height approximating $30 \mathrm{~m}$, which is typical, the above equations can be recommended.

Section 3 also discusses another length scale defined from the $\mathrm{nS}(\mathrm{n})$ spectrum (sometimes called the logarithmic spectrum) by

$$
\operatorname{Lmax}_{u}=\bar{U} / \text { nmax }_{u}
$$

where $n \max$ is the frequency of maximum energy [maximum value of $n S(n)$ ]. We do not recommend using this quantity as observed to calculate Lux as applied to a particular wind speed time series.

There is an additional topic treated in the extended Appendix C. This is the relations of the variance of the harmonic spikes in the spectrum of rotational turbulence to Eulerian variance and to other relevant dimensionless parameters. Because the principal required dimensional parameter is the elusive Luy, any numerical evaluations are highly uncertain. But, because 
observed results from Clayton data agreed well with modeled results based on an assumed value of $L_{u y}$, this material is given appendix status in this report. 


\section{CONTENTS}

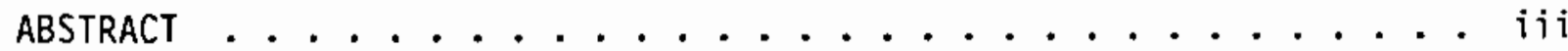

SUMMARY ............................... . . . .

NOMENCLATURE ..................................... ... ...

1.0 INTRODUCTION . . . . . . . . . . . . . . . . . . . 1.1

1.1 SCOPE AND INITIAL DEFINITIONS .............. $1 . .1$

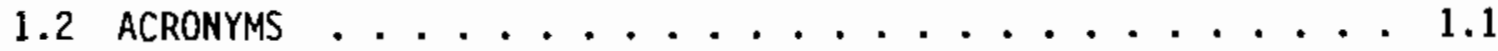

1.3 LiTERATURE CITING . . . . . . . . . . . . . . 1.2

1.4 ORGANIZATION OF THIS REPORT . . . . . . . . . . . . 1.3

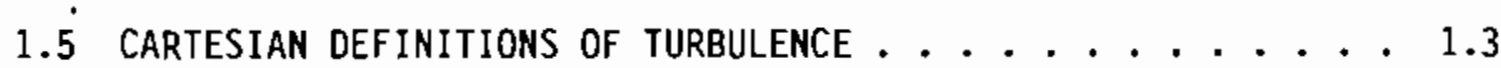

2.0 ESTIMATION OF TURBULENCE VARIANCE (EUV) IN THE

WIND TURBINE LAYER ...................... 2.1

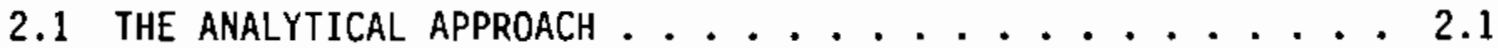

2.2 BIAS INTRODUCED BECAUSE OF STABILITY VARIATION

IN DATA . . . . . . . . . . . . . . . . . . 2.6

2.3 THE MEASUREMENT APPROACH . . . . . . . . . . . . . 2.7

2.4 CHANGE OF VARIANCE WITH HEIGHT OBSERVED IN WIND

ENERGY DATA . . . . . . . . . . . . . . . . . . . 2.9

2.5 OTHER VARIANCES OF TURBULENCE IN THE WIND TURBINE

LAYER ........................ 2.11

2.6 CONCLUDING REMARKS . . . . . . . . . . . . . 2.12

3.0 ESTIMATION OF THE INTEGRAL LENGTH SCALES OF TURBULENCE . . . . . . 3.1

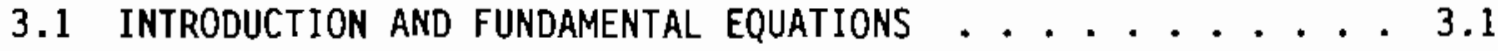

3.2 OPINIONS AND ILLUSTRATIONS . . . . . . . . . . 3.2

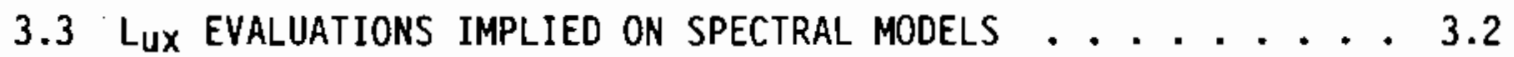

3.4 OBSERVED BEHAVIOR OF $\mathrm{L}_{\mathrm{uX}}$ AND $\operatorname{Lmax}_{\mathrm{u}} \ldots \ldots . . . \ldots$

3.5 RECOMMENDATIONS . . . . . . . . . . . . . . . . . 3.12

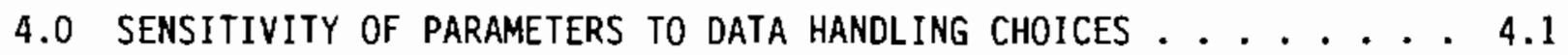


5.0 CONCLUSIONS $\ldots \ldots \ldots \ldots \ldots \ldots \ldots \ldots \ldots \ldots \ldots \ldots \ldots \ldots$

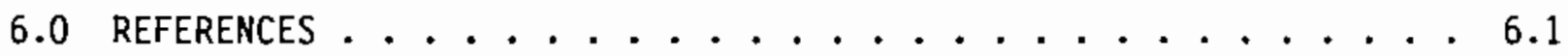

APPENDIX A - COMPARISON OF OBSERVED AND CALCULATED VARIANCES . . . A.1

APPENDIX B - EXPLANATION OF FRICTION VELOCITY, $u_{*}$, AND

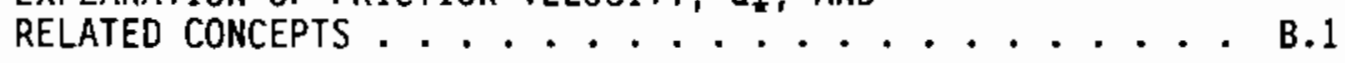

APPENDIX C - ROTATIONAL-EULERIAN RELATIONS, MODELED AND OBSERVED $\ldots c .1$

APPENDIX D - LINEAR AND QUADRATIC DETRENDING ROUTINE $\ldots \ldots \ldots . . \ldots 0.1$

APPENDIX E - DEFINITION OF AUTOCORRELATION FUNCTION . . . . . . E.1

APPENDIX $F$ - REVISED KAIMAL SPECTRUM FOR WIND ENERGY APPLICATIONS . . F.1

$\mathbf{x}$ 


\section{FIGURES}

2.1 Hypothetical Histogram of $\sigma_{u}^{2} \ldots \ldots . \ldots . \ldots 2 . \ldots$

2.2 Fraction of Variance Sampled Versus High-Frequency Cutoff, Assuming the Kaimal u-Spectrum ........... 2.9

2.3 Ratio of Observed/Calculated Variance, Wind Energy Data, Three Levels at Each Location . . . . . . . . . . . . 2.10

3.1 Kaimal u Spectrum for Neutral Stability . . . . . . . 3.3

$3.2 L_{u x}$ and the Ratio $L_{u x} / z$, Both Observed .......... 3.7

3.3 Choice of fmax $_{u}$ from four Spectra ............ 3.11

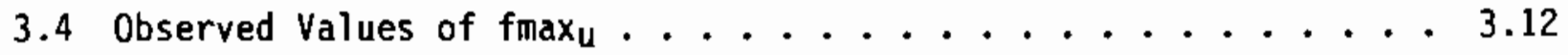

3.5 Quotient of Integral Scale by Scale of Maximum Energy . . . . 3.13

4.1 Change of EUV with Data Handling from Test to Test, Three Sites .................... 4.2

4.2 Change of Lux with Data Handling from Test to Test, Three Sites...................... 4.3

4.3 Change of Lmax $u$ with Data Handling from Test to Test, Three Sites .................. 4.4

\section{TABLES}

2.1 Surface Roughness Lengths for Various Surface Types . . . . . 2.2

3.1 Bias Shown in Three Data Sets in Observed Lux Versus Prediction from Equation (3.18) ......... 3.10

4.1 Mean Ratios Comparing Calculations Made with 4096 Data to Those Made with 2048 Data, $\Delta t=0.25 \mathrm{~s}$, 1st 0.D.

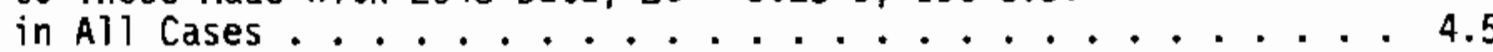





\section{NOMENCLATURE}

\begin{tabular}{|c|c|}
\hline EUV & Eulerian variance of $u, \sigma_{u}^{2},(\mathrm{~m} / \mathrm{s})^{2}$ \\
\hline H & hub height of $W T$, real or hypothetical, m \\
\hline$V(k P)$ & $\begin{array}{l}\text { variance calculated by integrating the spike centered about frequency } \\
k P \text { in the spectrum of turbulence in the rotational frame, where } 1 P \text { is } \\
\text { the frequency of rotation, }(\mathrm{m} / \mathrm{s})^{2}\end{array}$ \\
\hline Lux & integral length scale of $u$ in $x$ (longitudinal) direction, $m$ \\
\hline Luy & integral length scale of $u$ in $y$ (lateral) direction, $m$ \\
\hline$n$ & frequency, cycles per second, $\mathrm{Hz}$ \\
\hline$n(0)$ & frequency of blade rotation, $\mathrm{Hz}$ \\
\hline $\mathrm{R}$ & blade radius, m \\
\hline$R_{u}(t)$ & autocorrelation function of $u$ in time, dimensionless \\
\hline $\mathbf{R}_{\mathbf{u}}(\mathrm{x})$ & spatial autocorrelation function of $u$ in $x$ direction, dimensionless \\
\hline $\mathrm{R}_{\mathbf{u}}(\mathrm{y})$ & spatial autocorrelation function of $u$ in $y$ direction, dimensionless \\
\hline$S(n)$ & power spectral density, $\mathrm{m}^{2} / \mathrm{s}$ \\
\hline t & time, $s$ \\
\hline & mean wind speed for a period of time, $\mathrm{m} / \mathrm{s}$ \\
\hline$u, v, w$ & turbulence components in $x, y, z$ direction, respectively, $\mathrm{m} / \mathrm{s}$ \\
\hline & friction velocity, $\mathrm{m} / \mathrm{s}$ \\
\hline$x, y, z$ & Cartesian coordinates: alongwind direction, lateral, and vertical, m \\
\hline 20 & surface roughness length, m \\
\hline$\alpha$ & $R / L_{\text {uy }}$ \\
\hline$\beta$ & $\overline{\mathrm{U}} /(\omega \mathrm{Lux})$ \\
\hline$\sigma_{u}^{2}$ & variance of $\mathrm{u},(\mathrm{m} / \mathrm{s})$ \\
\hline
\end{tabular}





\subsection{INTRODUCTION}

\subsection{SCOPE AND INITIAL DEFINITIONS}

People in wind engineering and wind farming are interested in the level and scale of turbulence, principally because turbulence fatigues the wind turbine blades. The purpose of this report is give optimum information for evaluating the level and scale of turbulence as they apply to wind turbine operations at a particular location. By optimum information we mean that which has as much sophistication as is justified by the precision of input material expected in an environment of wind engineering and wind farming.

By turbulence level we mean the variance of the horizontal wind speed over a period of, say, $15 \mathrm{~min}$. By turbulence scale, we mean length over which turbutence maintains correlation in a given direction. We must consider at least two distinctions of direction. There is the direction of the mean wind, which is called the alongwind direction or the streamwise direction. Then there is the direction perpendicular to the mean wind direction. If we assume that the scale of turbulence in all directions perpendicular to the mean wind is the same, we still have two scales to deal with, one alongwind and one in the radial directions. These scales are called the integral scales. They are mathematically defined in Section 3.

A third topic of this report is estimation of the variances in the several hamonic spikes of the power spectrum of turbulence observed at a rotating point, as would be a point on a wind turbine blade. Because this material depends on very uncertain independent variable parameterization, it is relegated to Appendix $C$.

\subsection{ACRONYMS}

We need some acronyms. For turbulence variance we select EUV, which stands for Eulerian variance of the u-component of turbulence, which is the vector component of turbulence in the direction of the mean wind. At operational wind speeds the statistics of u are not significantly different from those of horizontal wind speed. In equations $\sigma_{u}^{2}$ means the same thing that EUV means in the text. 
The two integral length scales can be called Lux - integral length scale of $u$ in the alongwind direction, $x$, and $L_{u y}$ - integral length scale of $u$ in the lateral direction, $y$. We use HSV to designate the variance that is calculated by integrating one of the harmonic spikes of the spectrum of rotational turbulence across its frequency range--harmonic spike variance. The center frequencies of these spikes are called 1P, 2P, 3P..., or 1 per rev, 2 per rev, 3 per rev, where $1 P$ is the rotational frequency of the blade. And last, there is VPA for vertical plane array.

To summarize, the new acronyms are:

- EUV - Eulerian variance of u-component turbulence

- Lux - integral length scale of $u$ in alongwind direction

- Luy - integral length scale of u in lateral direction

- HSV - harmonic spike variance--rotational frame of reference

- VPA - vertical plane array.

\subsection{LITERATURE CITING}

The best source of turbulence description in the Eulerian frame in the atmospheric boundary layer is undoubtedly Atmospheric Turbulence by Panofsky and Dutton (1984). The projection of information shows that the authors are sensitive to the engineering point of view that wants description first and wants qualification and supporting mathematics later, if at all. On the other hand, the material is developed with sufficient rigor from first principles that the book is a genuine scientific text. 1t can be read and understood by graduate students in atmospheric turbulence. We can also recommend it for mature scientists and engineers in other mathematically oriented fields, since all purely meteorological terms used in the text are carefully defined.

For a one-paper review, perhaps the best is "Adiabatic Atmospheric Boundary Layers: A Review and Analysis of Data from the Period 1880-1972" by J. Counihan (1975). The term "adiabatic atmosphere" indicates the neutrally stable atmosphere, in which vertical temperature distribution does not either enhance or damp turbulent motions. The reason is that the vertical temperature distribution is such that as the temperature change encountered by a rising or falling parcel of air is the same as the temperature change made in the parcel 
by decreased or increased pressure as it rises or falls. This paper includes some models of variance and of length scales that were not included in Panofsky and Dutton (1984).

Another review document that has become a standard in the wind turbine engineering community is the Engineering Handbook on the Atmospheric Environmental Guidelines for Use in Wind Turbine Generator Development by Frost, Long and Turner (1978).

\subsection{ORGANIZATION OF THIS REPORT}

The two estimation methods given in this report for EUV and for $L_{u x}$ and Luy are so different that separate chapters of the report are given to each: Sections 2 and 3 , respectively. Section 4 cites and compares the behavior of calculated values of EUV and $L_{u x}$ when differences are made in sample length and exercise of detrending options. Also, the same description is included for another length scale, Lmaxu, defined as the quotient of the mean wind speed at hub height by the frequency $n$ of maximum energy in the spectrum nS(n), or $\mathrm{U} / \mathrm{nmax}$. Conclusions are given in Section 5 . There are also a nomenclature, a reference list, and six appendices.

\subsection{CARTESIAN DEFINITIONS OF TURBULENCE}

Consider the average wind vector over a given period of time. Define the direction of the horizontal projection of that vector as the $x$ direction of a Cartesian coordinate system, with the positive $y$ axis $90^{\circ}$ to the right and the $z$ axis pointing upward. Now consider the magnitude of the projection of the mean vector along the $x$ axis. In this report we call this the mean wind speed, or $\bar{U}$.

Now consider the instantaneous wind vector that was averaged to produce $\bar{U}$. Subtract the vector $(\bar{U}, 0,0)$ from the instantaneous vector. The remaining instantaneous vector $[u(t), v(t), w(t)]$ is turbulence as a function of time.

The statistics modeled in this report are statistics of $u(t)$. At wind speeds high enough to operate a wind turbine, statistics of $u(t)$ may be equated with statistics of horizontal wind speed. 
These definitions assume that the average value of the vertical component is zero, which is not true where the ground slopes. Then the average vector is $(\bar{U}, 0, \bar{W})$. The possibility of estimating onsite variance from the sum of variance of two or all three components, rather than $u(t)$ alone, is discussed in Subsection 2.5 . 


\subsection{ESTIMATION OF TURBULENCE VARIANCE (EUV) IN THE WIND TURBINE LAYER}

\subsection{IHE ANALYTICAL APPROACH}

Simple expressions for estimating EUV abound from the literature, and if one compares them, they seem to agree within some $25 \%$ to $30 \%$. But simple expressions for EUV are difficult to use with confidence because all of them require the so-called surface roughness length, zo. Such a formula, given by Frost, Long, and Turner (1978), is

$$
\sigma_{u}{ }^{2}=\left[\bar{U}(z) / \ln \left(z^{\prime} / z_{0}\right)\right]^{2}
$$

where $z$ should be some height between $10 \mathrm{~m}$ and $30 \mathrm{~m}$. This formula applies at neutral stability. The formula is somewhat misleading from an analytical point of view because theoretically EUV varies insignificantly over the height range 10 to $30 \mathrm{~m}$ in neutral stability. However, the required data for estimation of EUV are $U$ at a specific height $z$ and the surface roughness length $z_{0}$. According to the theory of the constant flux layer, the value so obtained may be applied from 10 to $50 \mathrm{~m}$ in neutral stability, if the mixing layer is at least $500 \mathrm{~m}$ deep, which it usually is (Panofsky and Dútton 1984, p. 113). Panofsky and Dutton (1984) provide equations that lead to approximately the same result, except that a coefficient of 0.96 instead of 1.0 is found in the numerator and inside the brackets for the second power (Appendix B).

The difficulty is evaluating $z_{0}$ for a particular site or, more exactly, evaluating zo for as many upwind sectors across the site within which the surface roughness is obviously different. The evaluation must be made by looking up a length in a surface roughness table. Any handbook or useful text on atmospheric turbulence has such a table. One of the best is given by Panofsky and Dutton (1984, see p. 121). The substance of their table appears here in Table 2.1. A shorter table is given by Frost, Long, and Turner (1978).

If the investigator's site is at all like California's Altamont Pass or Tehachapi Pass, these tables, with their listings of "text-book" surface descriptions, just don't fit. Frost, Long, and Turner (1978) further underscore the problem by assigning a range of an order of magnitude to some descriptions. For example, their table assigns the range of 0.1 to $1.0 \mathrm{~m}$ to 
TABLE 2.1. Surface Roughness Lengths for Various Surface Types

\begin{tabular}{|c|c|}
\hline$\underline{20}(\mathrm{~m})$ & Surface Type \\
\hline 1.3 & $\begin{array}{l}\text { Centers of cities with very tall buildings } \\
\text { very hilly or mountainous areas }\end{array}$ \\
\hline 1.0 & $\begin{array}{l}\text { Centers of large towns, cities } \\
\text { Forests }\end{array}$ \\
\hline 0.5 & Centers of small towns \\
\hline 0.4 & $\begin{array}{l}\text { Outskirts of towns } \\
\text { Fairly level wooded country }\end{array}$ \\
\hline 0.3 & Many trees, hedges, few buildings \\
\hline 0.08 & Many hedges \\
\hline 0.05 & $\begin{array}{l}\text { Few trees, summer time } \\
\text { Farml and } \\
\text { Long grass }(\approx 60 \mathrm{~cm}) \text {, crops }\end{array}$ \\
\hline 0.03 & $\begin{array}{l}\text { Isolated trees } \\
\text { Airports (runway area) }\end{array}$ \\
\hline 0.02 & $\begin{array}{l}\text { Uncut grass } \\
\text { Fairly level grass plains }\end{array}$ \\
\hline 0.01 & Few trees, winter time \\
\hline 0.007 & Cut grass $(\approx 3 \mathrm{~cm})$ \\
\hline 0.002 & Natural snow surface (farmland) \\
\hline 0.0009 & $\begin{array}{l}\text { Off-sea wind in coastal areas } \\
\text { Large expanses of water }\end{array}$ \\
\hline 0.0005 & Desert (flat) \\
\hline 0.0001 & $\begin{array}{l}\text { Calm open sea } \\
\text { Snow-covered flat or rolling ground }\end{array}$ \\
\hline 0.00001 & Ice, mud flats \\
\hline
\end{tabular}


the description "forest and woodland," and a range of 0.001 to $0.1 \mathrm{~m}$ to "mown grass." The point is that uncertainty of an order of magnitude in zo corresponds, according to Equation (2.1), to an uncertainty of a factor of about 2 in EUV. And, an onsite investigator could very well be faced with an uncertainty in $z_{0}$ of an order of magnitude if he tried any available table, regardless of the degree of precision to which the table pretended.

Frost, Long, and Turner (1978) also recognize that the final required descriptor of turbulence variance should be a probability distribution function. One obtains this probability distribution by calculating the wind speed variance within many periods of wind data, where each period is of the same length, say $15 \mathrm{~min}$. Then, if 100 such periods are analyzed, a histogram of 100 values of variance may be produced. The ensuing model of probability distribution is based on this histogram. The probability distribution recommended by Frost, Long, and Turner is actually for turbulence ms rather than variance. The recommended distribution is a Weibull function, which requires a scaling parameter and a shape parameter. But the dependence on $z_{0}$ does not go away. The required Weibull scaling parameter is a function of $z_{0}$.

Another way to arrive at a probability distribution function would be to begin with the site probability distribution for mean wind $U(H)$, which could be written

$$
\operatorname{Pr}\left\{\sigma_{u} 2(\bar{U})<\sigma_{u}^{2}\left(\bar{U}_{i}\right\}=\operatorname{Pr}\left\{\bar{U}<\bar{U}_{i}\right\}\right.
$$

where $\bar{U}$ is $\bar{U}(H)$ and where $\sigma_{u}^{2}(\bar{U})$ is given by an equation of the form of Equation (2.1). This is actually the probability model we reconnend. The table would have many lines, each corresponding to a different value of $i$. Now, the probability on the right,

$$
\operatorname{Pr}\left\{\bar{U}<\bar{U}_{i}\right\}=A_{j},
$$

can be estimated by a Weibull equation, if the required scaling and shape parameters that apply at the site are known. But, Justus, Hargraves, and Yalcin (1976) state that the Weibull shape parameter $k$ varied from 1.2 to 3.5 in order to describe their actual field data. Therefore, for a particular 
site, a measurement program may be the only way to determine the probability description of $\bar{U}(H)$ [Equation (2.3)] that fits the site.

In view of the foregoing discussion, our recomendation is that sitespecific turbulence variance be determined by direct measurement and analysis; any shortcuts that exclude measurement are too risky. The measurements should be carried out according to standardized procedures, which we recommend below.

Both the mean wind sample and the EUV sample should grow until each histogram looks believable and can be fitted to a Weibull distribution of the form

$$
\operatorname{Pr}\left\{x<x_{i}\right\}=1-\exp \left\{-\left(x_{i} / C\right)^{k}\right\}
$$

where $C$ and $k$ are Weibull parameters to be determined by curve-fitting to the distribution and have one pair of values for mean wind and another for EUv. On the other hand, it may be evident that integration of the believable histogram does not fit Equation (2.4), and that the only serviceable description of the onsite probability distribution of variance is a table empirically derived evaluating

$$
\operatorname{Pr}\left\{\sigma_{u}^{2}<\left(\sigma_{u}^{2}\right) i\right\}=A j
$$

for many arbitrarily chosen $i$. This is the model of last resort, pure empiricism, the very model this paper hopefully could make unnecessary. But it may be the onty advisable model for the investigator who has to pay the price of being wrong.

The connection between Equation (2.5) and a histogram is more easily seen if we rewrite the equation as

$$
\operatorname{Pr}\left\{\left(\sigma_{u}^{2}\right)_{i-1}<\sigma_{u}^{2}<\left(\sigma_{u}^{2}\right)_{i}\right\}=A_{i}
$$

for, say, $i=2, n$. There is really no more information in Equation (2.5a) than in Equation (2.5). However, if there are $n$ values of $i$, then $n$ lines 
of Equation (2.5) or (n-1) lines of Equation (2.5a) would be required to describe a given histogram. Now a histogram of variance corresponding to Equation (2.5a) could read:

$$
\begin{aligned}
& \operatorname{Pr}\left\{0<\sigma_{u}^{2}<0.5\right\}=0.08 \\
& \operatorname{Pr}\left\{0.5<\sigma_{u}^{2}<1.0\right\}=0.15 \\
& \operatorname{Pr}\left\{1.0<\sigma_{u} 2<1.5\right\}=0.29 \\
& \operatorname{Pr}\left\{1.5<\sigma_{u}^{2}<2.0\right\}=0.20 \\
& \operatorname{Pr}\left\{2.0<\sigma_{u}^{2}<2.5\right\}=0.16 \\
& \operatorname{Pr}\left\{2.5<\sigma_{u}^{2}<3.0\right\}=0.08 \\
& \operatorname{Pr}\left\{3.0<\sigma_{u}^{2}<3.5\right\}=0.03 \\
& \operatorname{Pr}\left\{3.5<\sigma_{u}^{2}<4.0\right\}=0.01 \\
& \operatorname{Pr}\left\{4.0<\sigma_{u}^{2}<i n f\right\}=\text { is less than } 0.01 .
\end{aligned}
$$

This is a hypothetical end result of modeling the wind speed according to Equation (2.5a) or (2.5). The result is illustrated in Figure 2.1.

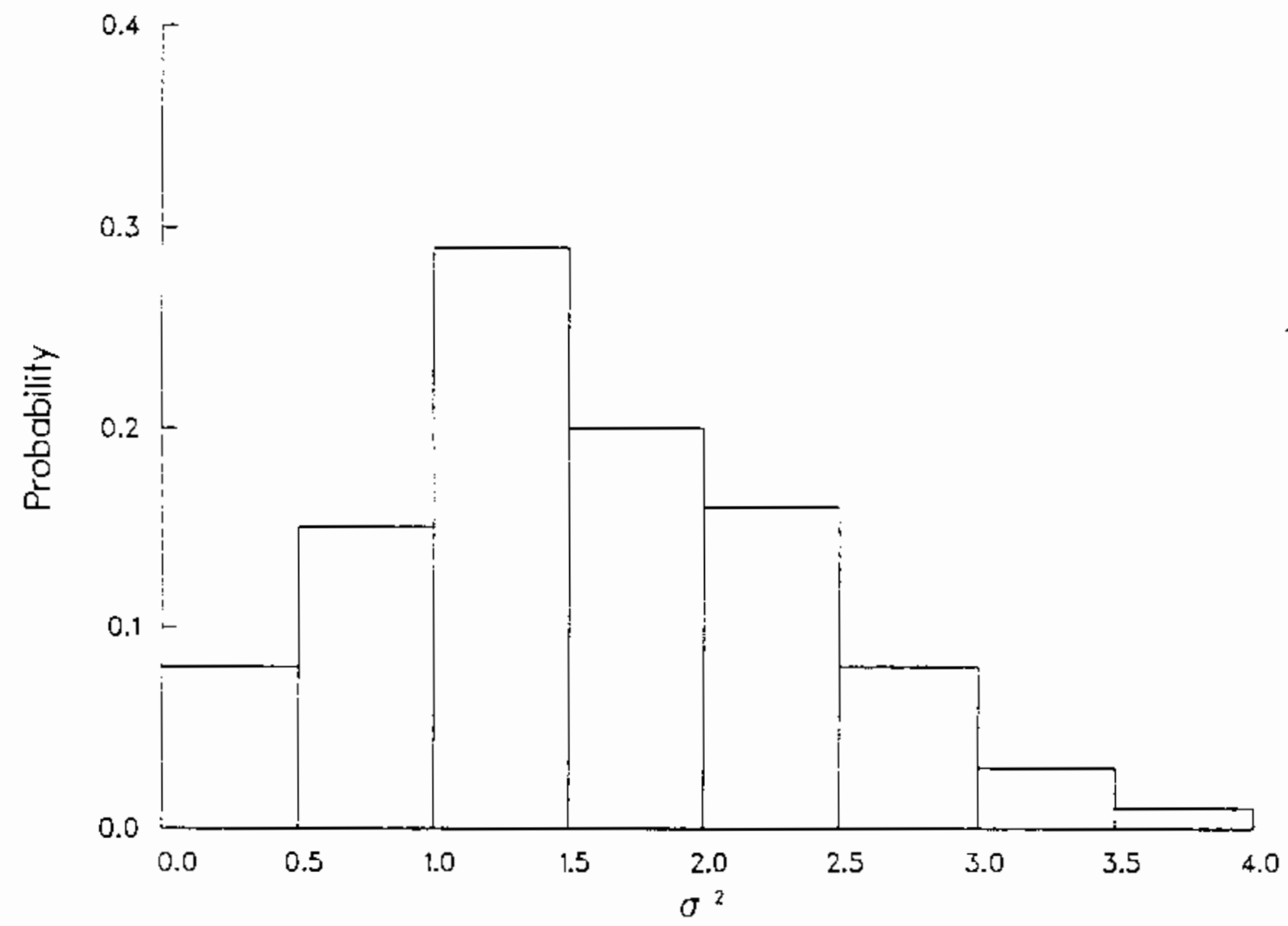

FIGURE 2.1. Hypothetica] Histogram of $\sigma_{u}^{2}$ 


\subsection{BIAS INTRODUCED BECAUSE OF STABILITY VARIATION IN DATA}

Going back to Equation (2.1), we consider the consequences of the lack of a stability parameter. Obviously, there will be a significant spread of EUV caused by stability variation for any one value of $\bar{U}(H)$. However, this spread is on top of a larger spread caused by variation of $\bar{U}(H)$ itself. Moreover, the stability variation decreases as mean wind increases. Therefore, in our simple model we ignore the spread caused by the stability variation.

However, it is also possible that a bias as well as a spread is introduced by neglecting stability. In order to estimate such a bias, we have analyzed two sets of data, selecting all those cases where the mean wind speed is at an operational level and where the stability is other than very stable, since Equation (2.1) does not apply at all to the very stable atmosphere. One was a group of ten tests from the clayton site and the other was a set of 20 tests from the 1968 Xansas data taken by the Air Force Cambridge Research Laboratory (AFCRL) group (Izumi 1971). Izumi's data volume covers 40 tests taken with anemometers at several heights, where the basic segments are 15 min and are grouped so that most of them organize in groups of four, making hourly periods. However, the basic segment analyzed was of $15-$ min duration. We used only the data from the 22.63-m height and only the first 15-min segment from each hour, and only if that $15-\mathrm{min}$ segment had a mean wind speed of $6 \mathrm{~m} / \mathrm{s}$ or higher. Twenty segments of AFCRL data were obtained in this way, making one data set.

For each AFCRL 15-min segment, a mean wind speed value and a standard deviation of the u component are given, along with many other analysis variables and parameters. The observed variances were calculated by squaring the standard deviations. No other adjustments were made. Estimated variance values were made using

$$
\sigma_{u}{ }^{2}=\left[\frac{0.96 \bar{U}(H)}{\ln \left(H / z_{0}\right)}\right]^{2}
$$

with the mean wind speeds in the data, with $22.63 \mathrm{~m}$ for $z$ and with $0.024 \mathrm{~m}$ for 20 , as recommended by Izumi in the data volume. 
The observed variances calculated from Clayton data were upwardly corrected by $6 \%$ to compensate for attentuation of the high-frequency portion of the signal by the anemometers (see Section 2.3).

This is indeed a small data sample. However, results from the two analyses are close enough to increase confidence. Specifically, the average ratios of the observed variance to the calculated (modeled) variance were 1.27 for the AFCRL data and 1.30 for the Clayton data.

Accordingly, we recommend the following modification of Equation (2.1) to estimate EUV in wind engineering contexts, provided that the investigator can estimate $z 0$ with reasonable confidence. The modified equation is

$$
\sigma_{u}{ }^{2}=1.2\left[\bar{U}(H) / \ln \left(H / z_{0}\right)\right]^{2} .
$$

Next, we consider recommendations for measurement.

\subsection{THE MEASUREMENT APPROACH}

The first requirement of estimating EUV by measurement is standardization, so that the same number calculated by different investigators at different sites will mean the same thing.

We recommend a standard time length such as $15 \mathrm{~min}$, possibly extended to $1000 \mathrm{~s}$ if the investigator wants the frequency $0.001 \mathrm{~Hz}$ in his power spectra. This recommendation is consistent with that used in the landmark turbulence study by the AFCRL group as described by Izumi (1971). We also recommend that instantaneous data be taken at an interval not greater than $5 \mathrm{~s}$. If the data are instantaneous, rather than averaged over the sampling interval, the use of a longer sampling interval does not necessarily bias variance caiculations. But confidence in each variance calculation is reduced as the sampling interval is increased for the simple reason that the data sample is smaller.

Another consideration in setting the sampling interval is the loss of high frequency sensitivity imposed by the length constant of the anemometers (Horst 1973). If $L$ is the length constant, then the half-power frequency $n(1 / 2)$ for a propeller anemometer is given by 


$$
n(1 / 2)=U / 2 \pi L
$$

where $U$ is mean wind speed. For example, if $L$ is $3 \mathrm{~m}$ and $U$ is $10 \mathrm{~m} / \mathrm{s}, n(1 / 2)$ is about $0.5 \mathrm{~Hz}$. Nothing is gained by a sampling interval shorter than the reciprocal of $n(1 / 2)$. If the effective upper-frequency limit is this high, there need be no concern about loss of calculated variance caused by highfrequency truncation. However, micrometeorological models of variance, such as Equation (2.6), are based on effective upper-frequency limits of about $10 \mathrm{~Hz}$. If the effective upper-frequency limit for a given data sample is $1.0 \mathrm{~Hz}$, the loss of calculated variance is about $5 \%$ to $10 \%$. If the upperfrequency limitation is $0.5 \mathrm{~Hz}$, the loss of calculated variance is about $10 \%$ to $15 \%$. In either case, the lower the height, the greater the loss.

Let us assume that EUV as reported in the micrometeorological literature is based on a integration of the spectrum over a frequency range from 0.001 to $10.0 \mathrm{~Hz}$. Then, the loss of variance caused by high-frequency truncation, based on the Kaimal u spectrum of turbulence for the neutral atmosphere, is given by Figure 2.2 .

Any time series of field wind data should be linearly detrended before variance is calculated. Heuristically, the suggestion applies to a time series with obviously increasing or decreasing values over its entire length so that a slope is clearly seen in a plot of the time series. Technically, this means calculating the best-fitting linear polynomial to the particular time series,

$$
f(k)=A+B k, \quad 0<k<N-1
$$

where the time series consists of $N$ data. The mean of such a series is $A+$ $B / 2$, and the slope $B$ is a measure of the trend. A detrending subroutine is included in Appendix D. This subroutine was constructed following Hylie (1966, pp. 130-134). By option, either the best-fitting linear polynomial or the best-fitting quadratic polynomial may be computed and subtracted from the data. Only the linear removal is recomended. 

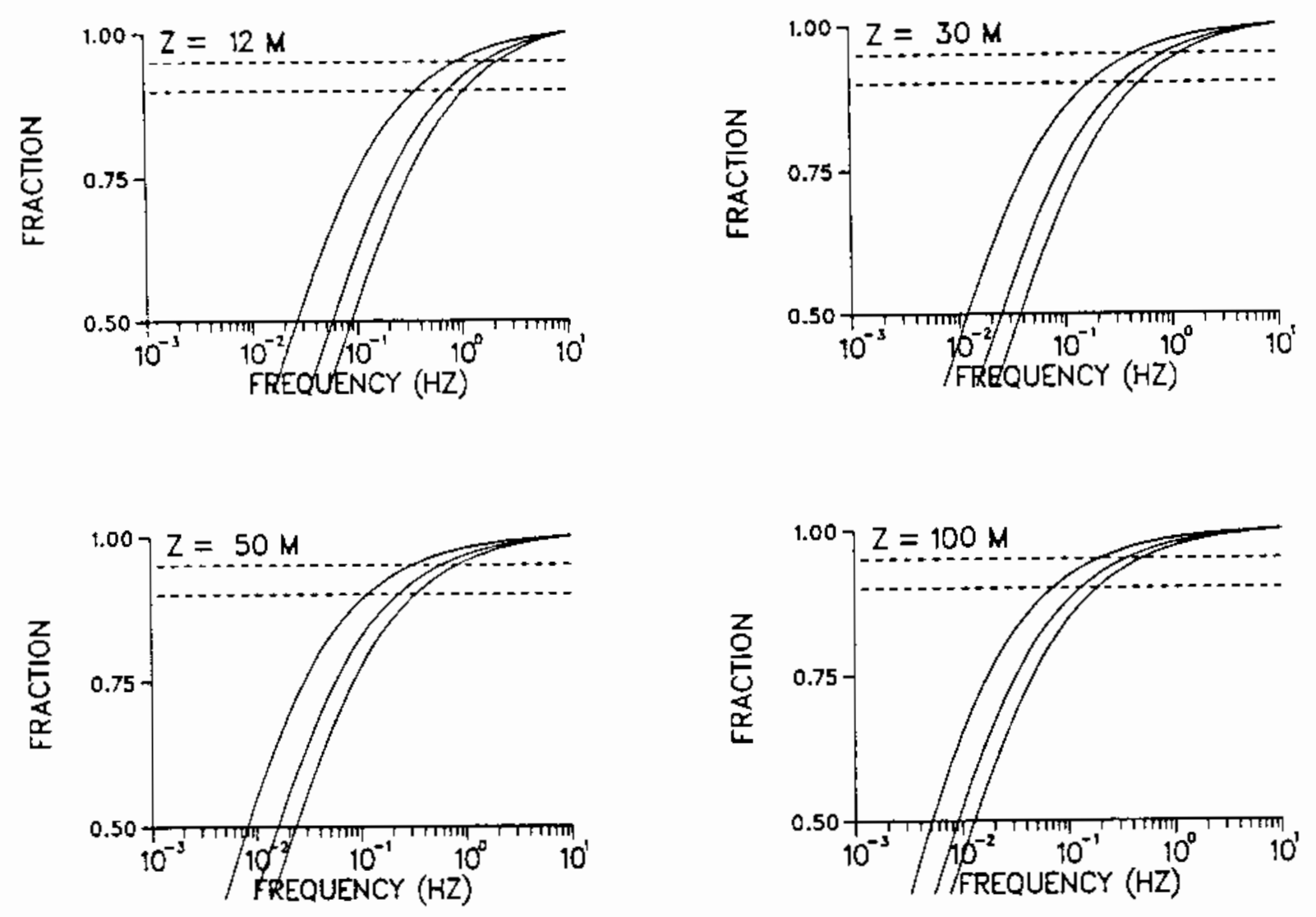

FIGURE 2.2. Fraction of Variance Sampled Versus High-Frequency Cutoff, Assuming the Kaimal u-Spectrum ( $U=6,14$, $22 \mathrm{~m} / \mathrm{s}$, left to right on same graph; dashed lines at $90 \%$ and $95 \%$ )

\subsection{CHANGE OF VARIANCE WITH HEIGHT OBSERVED IN WIND ENERGY DATA}

Actually the data gathered under various federally sponsored wind energy programs and analyzed for this report were not 1 imited to the Clayton data. Data were also analyzed that originated at:

San Gorgonio Pass - VPA of 6 anemometers - 12 tests analyzed Altamont Pass - VPA of 8 anemometers - 6 tests analyzed.

San Gorgonio Pass is in southern California just west of Palm Springs. Altamont Pass is in central Calfornia just east of San Francisco Bay, or more exactly, just east of Livermore. The 12 San Gorgonio tests were well dispersed over September and 0ctober 1987. The six Altamont tests are more like two tests because they are two periods on August 20 and 21, 1987, of three 
contiguous measurement periods each. Moreover, one of the anemometers in the Altamont VPA was not functioning correctly. The variance of the data taken from this anemometer is notably less than that taken from the other anemometers.

There is no reason, from theory for a neutral boundary layer over homogeneous terrain, why the ratios between observed and calculated (modeled) variance should be a height-dependent quality. But the observed data are for a variety of stabilities, and the terrain at all sites has some upwind features. Therefore, it is not surprising to find that the ratios are height-dependent. The ratios decrease with height at clayton. The ratios appear to increase with height at the other sites. These observations are shown in Figure 2.3.

We emphasize that only the apparent height-dependence is of interest in Figure 2.3, not the absolute values of the ratios. That is because only for the clayton site has a $z 0$ value been obtained by analyzing carefully selected profiles of mean wind data, $\bar{v}(z)$. The $z_{0}$ values used to estimate the variance

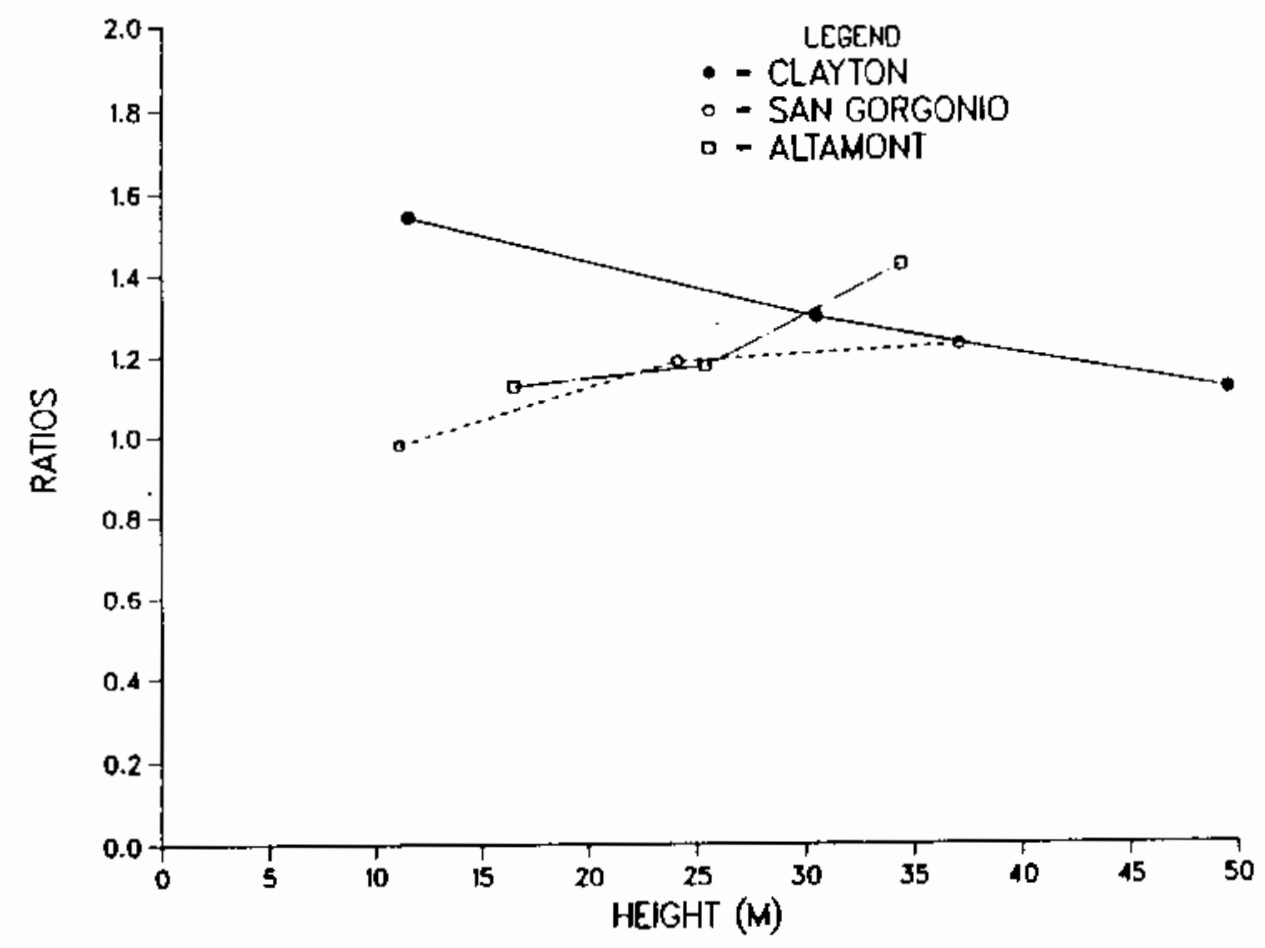

FIGURE 2.3. Ratio of Observed/Calculated Variance, Wind Energy Data, Three Levels at Each Location 
ratios at San Gorgonio and Altamont were arrived at by interpreting spectral analysis of the present data sets. That is the same as using part of the variance to predict the variance. Therefore, the absolute values of the ratios from the San Gorgonio and Altamont data represent no test. The absolute values of the ratios from the clayton data are the only ones that are valid in this sense.

\subsection{OTHER VARIANCES OF TURBULENCE IN THE WIND TURBINE LAYER}

We have presented the variance of horizontal wind speed as being about the same as the variance of u-component turbulence. The choice of this variance is really equivalent to saying that the change of wind direction does not contribute to fatigue. Change of direction would be a factor, if we model the following:

$$
\begin{aligned}
& \sigma_{u}^{2}+\sigma_{v}^{2} \\
& \sigma_{u}^{2}+\sigma_{v}^{2}+\sigma_{w}^{2} .
\end{aligned}
$$

In other words, we may ask, is fatigue proportional to $\sigma_{u}^{2}$, to the sum of $\sigma_{u}^{2}$ and $\sigma_{\mathrm{v}}{ }^{2}$, or to the sum of $\sigma_{\mathrm{u}}{ }^{2}, \sigma_{\mathrm{v}}{ }^{2}$, and $\sigma_{\mathrm{W}}{ }^{2}$ ? The following estimations may be used to relate these quantities over homogeneous level terrain.

$$
\begin{aligned}
& \sigma_{u}^{2}+\sigma_{v}^{2}=1.3 \sigma_{u}^{2} . \\
& \sigma_{u}^{2}+\sigma_{v}^{2}+\sigma_{w^{2}}^{2}=1.4 \sigma_{u}^{2} .
\end{aligned}
$$

Over complex terrain the last sum is probably greater, perhaps approaching $2 \sigma_{\mathrm{U}}{ }^{2}$.

The investigator really should measure all three onsite component variances and then decide whether to use only $\sigma_{u}{ }^{2}$ or one of the sums in Equations (2.9) and (2.10) in the model. Then if, say, the left side of Equation (2.10) is used, the right side should be determined from onsite measurement, particularly if the ground is sloping. 
If, for example, the left side of Equation (2.10) is used and the sum is $2 \sigma_{\mathrm{u}}{ }^{2}$, then the effective, theoretical model is twice the value given in Equation (2.7).

\subsection{CONCLUDING REMARKS}

EUV will not necessarily be relatively constant over a layer of any significant thickness over typical wind farm terrain. Therefore, we reconmend:

1. There should be three heights of measurement (hub height and the two extreme heights of the blade). However, if the blade is less than $20 \mathrm{~m}$ in diameter, one height (the hub height) should be sufficient.

2. Data should be taken in standardized periods such as $15 \mathrm{~min}$.

3. Data samples should be instantaneous, and, ideally, should be at equally spaced intervals not greater than $5 \mathrm{~s}$.

4. If the distance constants of the instruments are greater than $2 \mathrm{~m}$, measured variances should be upwardly corrected (Figure 2.3). At least, such corrections should be considered.

5. Each data segment so taken should be linearly detrended before the variance is calculated (Appendix D). 


\subsection{ESTIMATION OF THE INTEGRAL LENGTH SCALES OF TURBULENCE}

\subsection{INTRODUCTION AND FUNDAMENTAL EQUATIONS}

In this section we look for models of integral length scale that apply to the u-component of turbulence within the height range of the wind turbine layer: 1) as it is correlated in the alongwind direction and 2) as it is correlated in the lateral directions. (These are the scales called Lux and $L_{u y}$ in Section 1.) This section ends by suggesting models that will hopefully be useful for wind engineering and wind farming purposes. The reader who is not interested in detail is directed away from this section and toward the brief part in the Summary that treats these scales.

Both $L_{u x}$ and $L_{u y}$ are difficult to evaluate using atmospheric boundarylayer data. Luy is many times more difficult to evaluate than Lux because data from many anemometers are required to calculate a value of Luy while data from only one anemometer are required to calculate a value of $L_{u x}$. Both are based on a physical concept that turbulence exhibits a spatial correlation over separation distances not exceeding a certain limit beyond which turbulence is uncorrelated, because the largest "eddies" that make up turbulence do not exceed that limit. The upper limit to the distance over which turbulence exhibits a correlation is on the order of the lengths defined below by

$$
\begin{aligned}
& L_{u x}=\int_{0}^{\infty} R_{u}(x) d x, \\
& L_{u y}=\int_{0}^{\infty} R_{u}(y) d y .
\end{aligned}
$$

where $R_{u}$ is the autocorrelation function of $u$ in either the $x$ or $y$ direction. The autocorrelation is defined in Appendix $E$. Both of these equations imply that measurements at many points are needed so that $R_{U}$ can be calculated. A crucial simplification called Taylor's hypothesis can be made for calculation of Lux. We assume that the spatial correlation in the $x$ direction and the time correlation in the time record are similar such that we may substitute the autocorrelation in time $R_{U}(t)$ for $R_{U}(x)$ and $U d t$ for $d x$ and write 


$$
L_{u x}=\bar{U} \int_{0}^{\infty} R_{u}(t) d t,
$$

because $R_{u}(x)=R_{u}(t)$ when $\bar{U} t=x$. Thus $L_{u x}$ can be calculated using the wind data from only one anemometer. Within our context $L_{u y}$ must be estimated by applying some additional assumption to an evaluation of Lux. One is supplied in Equation (3.22).

\subsection{OPINIONS AND ILLUSTRATIONS}

Equations (3.1) and (3.3) do not hint at any criterion for determining the length scales that is extrinsic to the turbulence. However, power spectral models for the neutral wind-turbine layer indicate that Lux must be some multiple of height. Analys is of field data shows that $L_{u x}$ increases with height, but at a considerably lower power than 1. Therefore, we need to look at where the spectral models must be wrong. That they are wrong is well known, as is implicit from the length-scale formulations in Counihan's paper.

Panofsky and Dutton (1984) suggest that scales of this type be avoided. One reason is that integrals like Equation (3.3) for $u$ and $v$ are difficult to evaluate using atmospheric data because no stationary value of the integral is encountered as the upper limit of integration is increased. However, we need to tie the lack of confidence in length scales to that part of the spectrum that predicts length scale value, namely, the low-frequency side.

\subsection{LuX EVALUATIONS IMPLIED ON SPECTRAL MODELS}

The integral scale and another length scale that may be of interest can both be derived from the spectrum of turbulence. Therefore, we introduce at this point the Kaimal spectrum of u-component turbulence in neutral stability. This spectrum is in terms of a dimensionless frequency

$$
f=n z / \bar{U} .
$$


The equation, itself dimensionless, is

$$
\frac{n S_{u}(n)}{u_{\star}^{2}}=\frac{105 f}{(1+33 f)^{5 / 3}}
$$

where $u_{\star}$ is the friction velocity (Appendix B). The graph of the spectrum is shown in Figure 3.1 .

Micrometeorologists have shown how three length scales can be derived from this spectrum, one from each slope of it and one from the frequency of the peak. But, however, many length scales can be calculated from this spectrum, there is only one independent length scale in it and that scale is the height, $z$. Then it follows that, according to this model, each of the three scales must be some constant multiple of $z$. The integral scale may be computed from the left side of the spectrum, as is shown below. The scale of maximum energy may be calculated from the frequency at the peak of the spectrum. The length

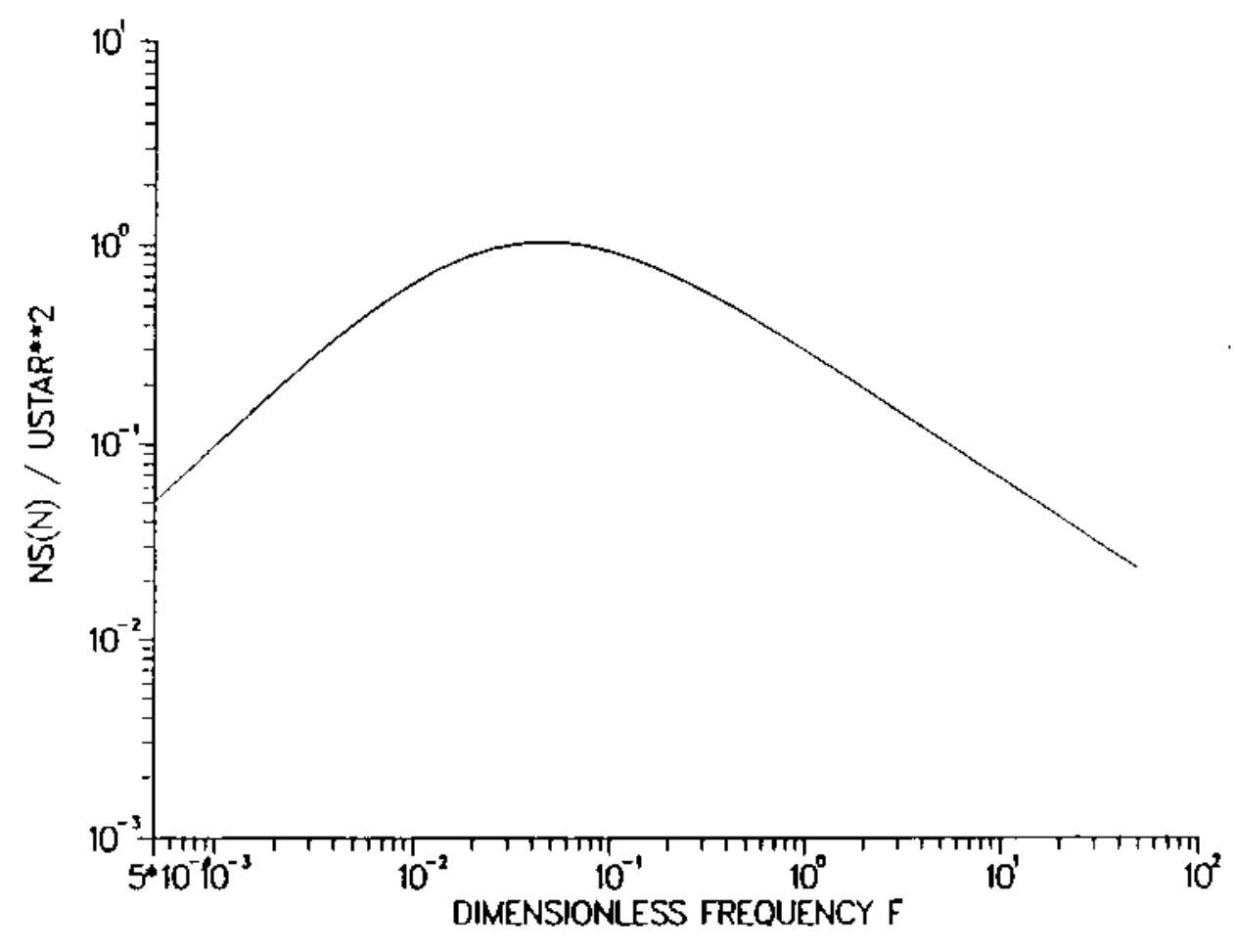

FIGURE 3.1. Kaimal u Spectrum for Neutral Stability 
scale that may be computed from the right side is, so far as we know, of no interest in a WEF context. Therefore we shall concentrate on the other two length scales.

Let us call the length scale that corresponds to the frequency of maximum value of $n S(n) L_{\text {max }}$. This is sometimes called the length scale of the energy- . containing eddies. Then

$$
\operatorname{Lmax}_{\mathrm{u}}=\tilde{\mathrm{U}} / \mathrm{fmax}_{\mathrm{u}}
$$

where $\operatorname{fmax}_{u}$ is the value of $f$ in Figure 3.1 where the spectrum attains its maximum value. This turns out to be

$$
f_{\max }=0.046 \text {. }
$$

By combining Equations (3.4), (3.6) and (3.7), we obtain

$$
\operatorname{Lmax}_{u}=22 \mathrm{z} .
$$

To derive the constant multiple relating the integral scale $L_{u x}$ to height $z$, we begin with the theoretical relation between the spectrum and the autocorrelation for a stationary process, given by

$$
S_{u}(n)=4 \sigma_{u}^{2} \int_{0}^{\infty} R_{u}(t) \cos (2 \pi n t) d t
$$

Now we can write

$$
S_{u}(0)=4 \sigma_{u}^{2} \int_{0}^{\infty} R_{u}(t) d t
$$

and

$$
S_{u}(0)=\lim _{n \rightarrow 0} \frac{n S_{u}(n)}{n} .
$$


Now combining Equations (3.3), (3.9), (3.10), and (3.11), we obtain

$$
L_{u x}=\frac{\bar{U}}{4 \sigma_{u}{ }^{2}} \lim _{n \rightarrow 0} \frac{n S_{u}(n)}{n} .
$$

From Equation (3.5)

$$
\lim _{n \rightarrow 0} \frac{n S_{u}(n)}{n}=105 u_{\star}^{2} z / \bar{U}
$$

Therefore

$$
L_{u x}=26.25 \frac{u_{*}{ }^{2}}{\sigma_{u}{ }^{2}} z .
$$

Now, by integrating Equation (3.5) over all frequencies, we obtain

$$
\frac{\sigma_{u}^{2}}{u_{*}^{2}}=4.5 \text {. }
$$

But, from Panofsky and Dutton (1984), we obtain

$$
\sigma_{u^{2}} 2 / u_{\star}^{2}=5.7
$$

Therefore, from Equation (3.14); we obtain, using Equation (3.15),

$$
L_{u x}=5.8 \mathrm{z}
$$

which is "pure Kaimal," and using Equation (3.16),

$$
L_{u x}=4.6 \mathrm{z} \text {. }
$$


We have sacrified purity and used Equation (3.18) for our model in the Figure 3.2 .

To summarize, we now have two length scales that are fixed multiples of z. They are

$$
\begin{aligned}
L_{u x} & =4.6 \mathrm{z} \\
\operatorname{Lmax}_{u} & =22 \mathrm{z} .
\end{aligned}
$$

Note that $\lim n \rightarrow 0[\mathrm{nS}(n) / n]$ can be evaluated from the slope on the left side of the Kaimal spectrum (see Figure 3.1). That is why we say the integral scale relates to the left side of the spectrum.

Note also the two ratios given for $\sigma_{u} 2 / u_{\star}{ }^{2}$, which are 4.5 and 5.7 . This is why we said in Section 2 that there is a 25 to $30 \%$ difference in modeled estimates of $\sigma_{\mathrm{U}}{ }^{2}$. Another estimate of this ratio, 4.8, can be obtained from Hojstrup (1982), which proposes spectra for the unstable boundary. Hojstrup's equations yield the ratio 4.8 as the neutral limit of the unstable boundary layer is approached. For the u-spectrum recommended by Frost, Long, and Turner (1978, p. 4-18), the ratio is only 2.8 .

Another interesting and very briefly treated example is the von Karman spectrum for $u$. It is given by

$$
n S_{u}(n)[V K]=4 \sigma_{u}^{2} F /\left[1.0+70.78 F^{2}\right] 5 / 3 .
$$

where $F=n L / U$, and where $L$ is an unspecified length scale. If we derive $L u x$ from this expression the same way we derived it from Equation (3.12), we obtain simply

$$
L_{u x}(V K)=L \text {, }
$$

indicating that $L$ is meant to be the integral scale rather than one of the other two length scales. 

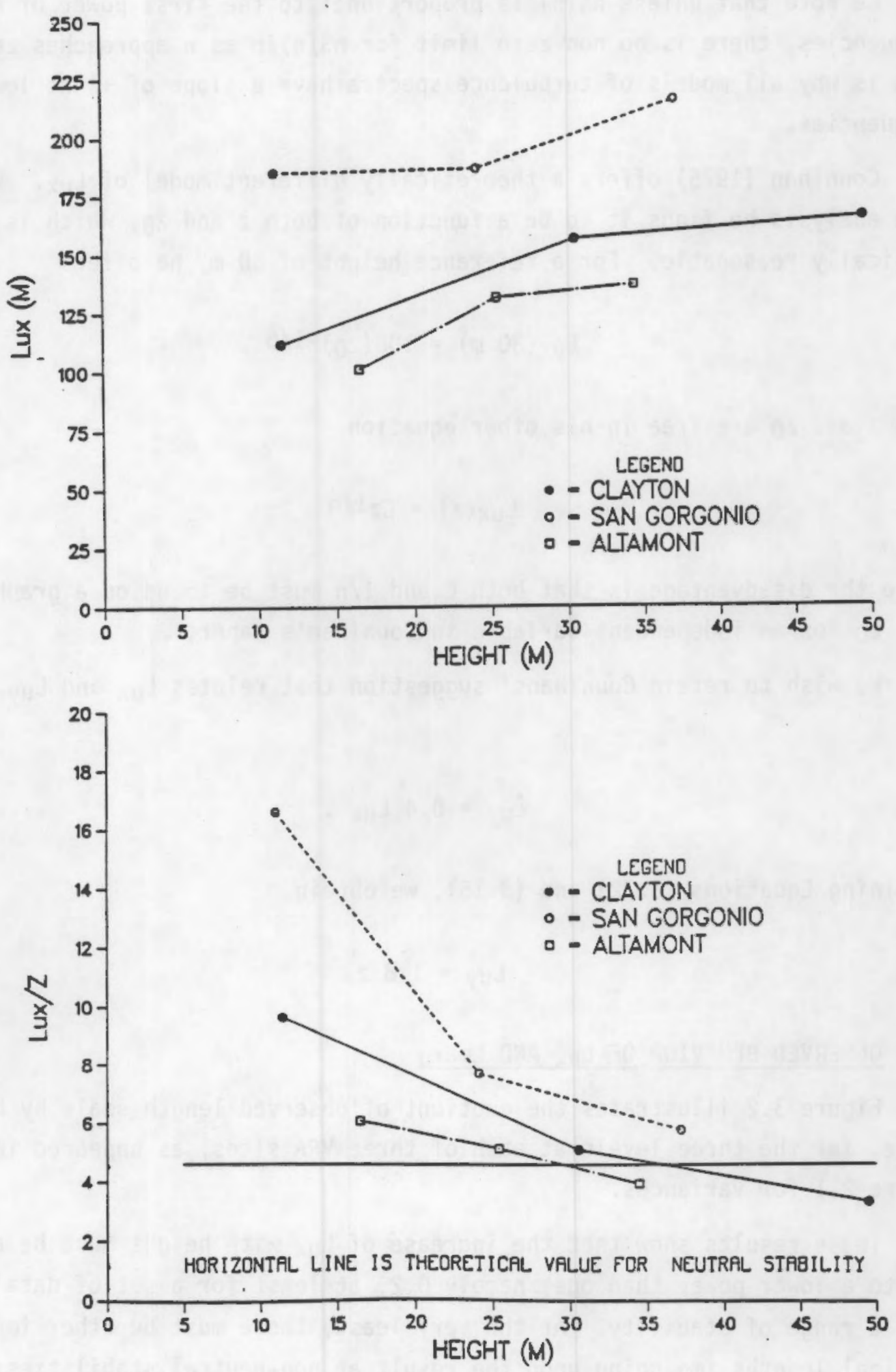

FIGURE 3.2. Lux and the Ratio $L_{u x} / z$, Both Observed 
We note that unless $n S(n)$ is proportional to the first power of $n$ at low frequencies, there is no non-zero limit for $n S(n) / n$ as $n$ approaches zero. That is why all models of turbulence spectra have a slope of +1 at low frequencies.

Counihan (1975) offers a theoretically different model of Lux. From data analysis he finds it to be a function of both $z$ and $z_{0}$, which is physically reasonable. For a reference height of $30 \mathrm{~m}$, he offers

$$
L_{u x}(30 m)=108\left(z_{0}\right)^{-1 / 6}
$$

Both $z$ and $z_{0}$ are free in his other equation

$$
L_{u x}(z)=C_{z} 1 / n
$$

where the disadvantage is that both $C$ and $1 / n$ must be found on a graph that uses $z_{0}$ for an independent variable in Counihan's paper.

We wish to retain Counihans' suggestion that relates $L_{u x}$ and $L_{u y}$, which is

$$
L_{u y}=0.4 L_{u x} \text {. }
$$

Combining Equations (3.22) and (3.18), we obtain

$$
L_{u y}=1.8 \mathrm{z} .
$$

\subsection{OBSERVED BEHAVIOR OF Lux AND Lmax}

Figure 3.2 illustrates the quotient of observed length scale by height, $L_{u x} / z$, for the three levels at each of three VPA sites, as appeared in Figure 2.1 for variances.

These results show that the increase of Lux with height must be according to a lower power than one, namely 0.2 , at least for a set of data taken over a range of stability. At the very least, there must be other important physical lengths impinging upon the result at non-neutral stabilities, and perhaps at neutral stability as well. This finding agrees qualitatively with 
Counihan's equation [here, Equation (3.21)], which also yields an increase of Lux according to a lower power of height than one, because $1 / n$ from his graph is always less than one. But the magnitude of estimate obtained for the Clayton site from either of Counihan's equations, about $260 \mathrm{~m}$, is well above those we calculated for the site from data analysis (see Figure 4.2 in next section).

Also, we note in this sample that Lux appears to be greater at San Gorgonio than at the other two sites. This may result from the greater complexity of terrain at the San Gorgonio site.

The physical reason for difficulty in evaluating $L_{u x}$ is, of course, that there are physical factors other than the height above ground that impinge. From the point of view of the Kaimal spectrum, the problem is in the fact that as stability varies as it does under operating conditions, only the right side of the spectrum is sufficiently invariant to be useful for wind engineering purposes without further modeling that goes beyond the present state of the art. Kaimal et al. (1972) show that the left side jumps discontinuously to the left as stability passes through neutral from stable to unstable. Theoretically, the position of the left side of the spectrum can be specified for the unstable atmosphere if one is able to measure two additional length scales that are very briefly mentioned at the end of Appendix B (Hojstrup 1982). But, as explained in Appendix $B$, the instrumental and analytical requirements for evaluating these lengths are not practical in a wind engineering program. Therefore, the effective left side of the spectrum remains extremely variable within the operational wind environment, and the effective value of $L_{u x}$ is correspondingly variable.

Equations (3.15) and (3.16) indicate that the variance obtained by integrating the Kaimal spectrum is less than that predicted from an equation in Panofsky and Dutton (1984) for neutral stability. Panofsky and Dutton arrived at their value by reviewing works of several investigators. The Kaimal spectrum is easily so as to increase the variance to $5.7 u_{\star}{ }^{2}$ by elevating the left side while the better-known right side remains fixed. In Appendix $F$ such a modification is suggested, along with other like modifications that bring the variance up to 1.3 times the expected neutral value, as was found representative of variances in wind data taken at operational speeds (Section 2). 
Again, we emphasize the real troubles with modeling length scales for wind engineering purposes:

- The greatest uncertainty is about Luy, which is the most relevant (Appendix C).

- At the variety of stabilities that encompass operating conditions, a model of Lux must be something other than a linear function of height.

We can show, as we did with the variance, how much bias our data show from $L_{u x}$ as given in Equation (3.18). These biases are shown in Table 3.1. Except for San Gorgonio, these bias ratios are not greatly different from those found for the variances (Section 2). These were 1.30 for Clayton data and 1.27 for AFCRL data.

We next look at the behavior of $\operatorname{Lmax}_{u}$ in the same way; then we compare the two scales. "Observed" values of Lmaxu are produced by examining the graphs of banded spectra of the field wind data, such as the four examples shown in Figure 3.3.

There are about 25 logarithmically banded spectral estimates to choose from plus the unbanded estimates for the lowest three harmonics of the data analysis.

Lmax $u$ becomes $U$ divided by the value of $f_{\max } u$ chosen from such spectral curves by inspection. The choice is not without subjectivity. If there is a saddle in the spectrum with two approximately equal peaks, the frequency midway between the two peaks may be chosen for fmaxu. If the peak is at one of the

TABLE 3.1. Bias Shown in Three Data Sets in Observed Lux Versus Prediction from Equation (3.18)

\begin{tabular}{|c|c|c|c|c|}
\hline Data & $\begin{array}{l}\text { Hub Height } \\
\text { (m) }\end{array}$ & $\begin{array}{l}\text { Average } \\
\text { Lux }_{\text {um }}(\mathrm{m})\end{array}$ & Ratio & $\begin{array}{l}\text { Bias Ratio } \\
\text { (Ratio/4.6) }\end{array}$ \\
\hline Clayton & 30.5 & 156.0 & 5.1 & 1.1 \\
\hline San Gorgonio & 24.1 & 186.0 & 7.7 & 1.7 \\
\hline Altamont & 25.4 & 131.0 & 5.2 & 1.1 \\
\hline
\end{tabular}


CO1011247 SPECD

IST OROER OCTREND, 4096 OATA

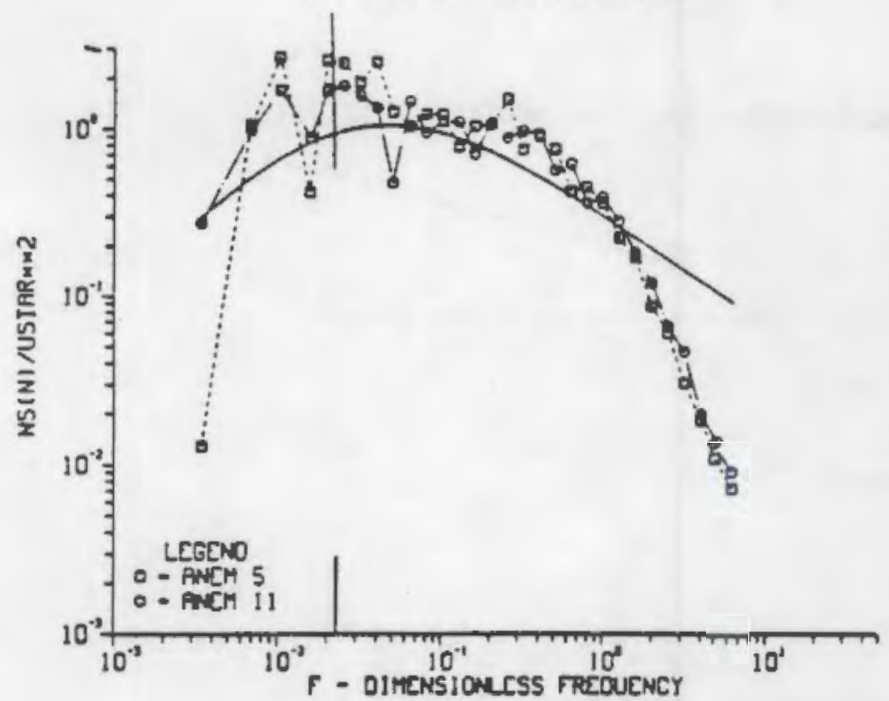

colol1eoz sमय

15T ORDER OCTREND, 4096 ORTR

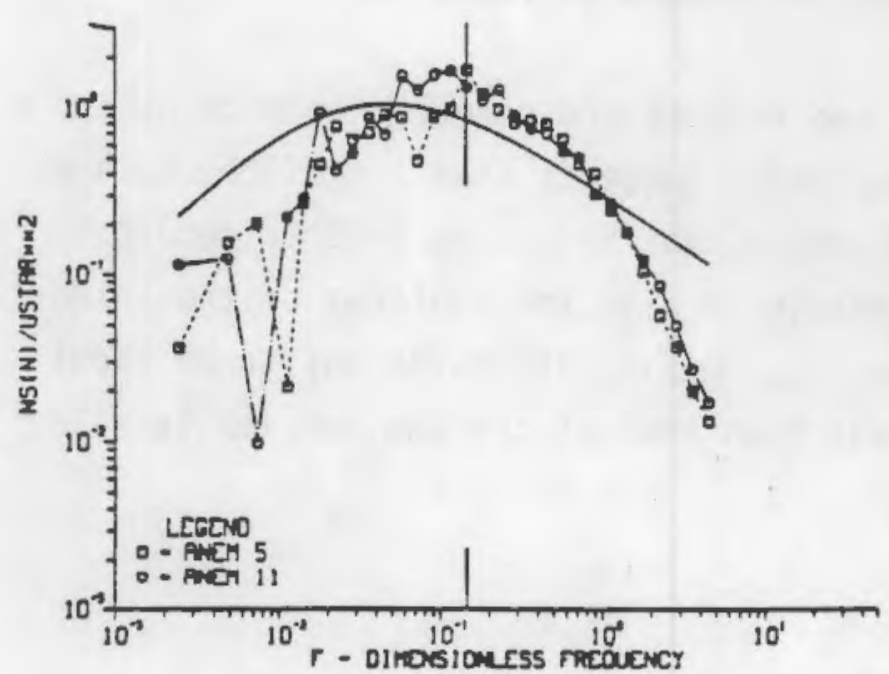

CO1011543 SPEED

15T OROER DCTRENO, 4096 OATA

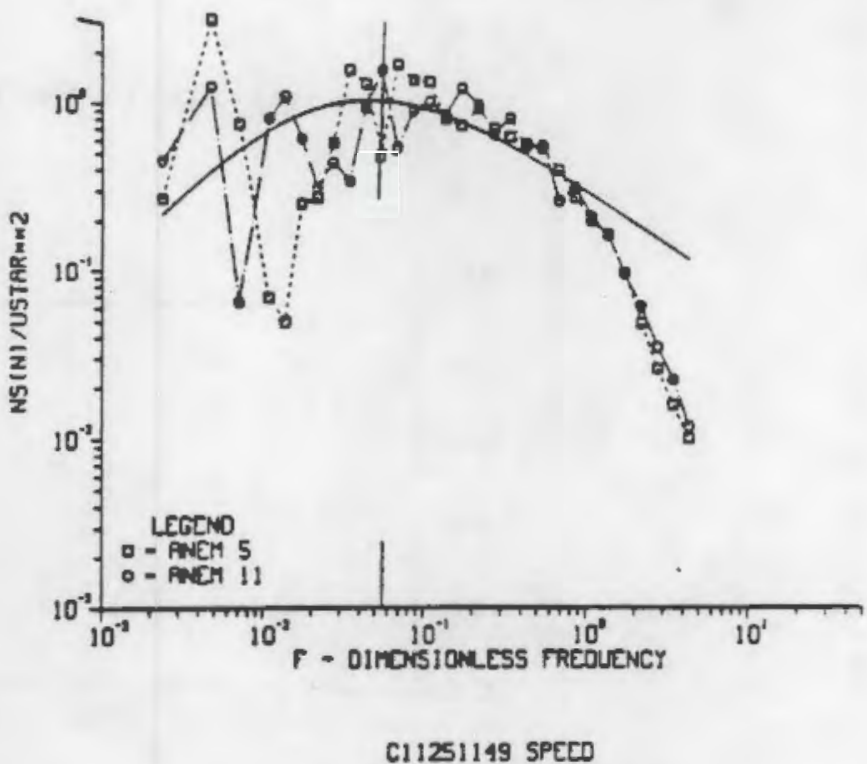

IST OROER DETRENO, 4096 OATA

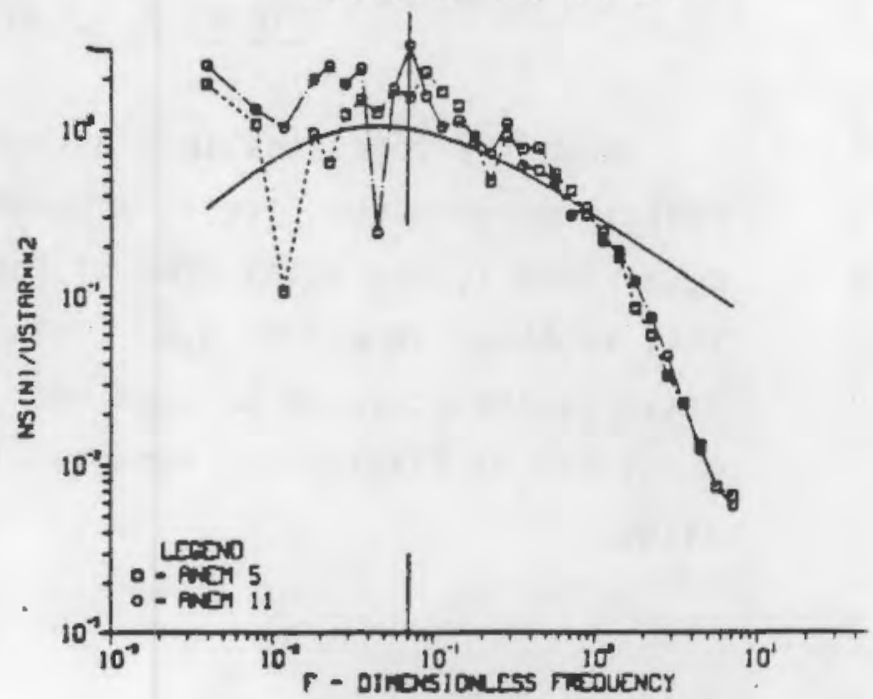

FIGURE 3.3. Choice of $\operatorname{fmax}_{u}$ from Four Spectra

three unbanded low frequencies, the frequency of the peak is chosen only if $\mathrm{nS}(\mathrm{n})$ is high at neighboring estimates as well. This is because of the large statistical variance of unbanded estimates.

As stated above, fmaxu for the $u$ spectrum should be 0.046 . Figure 3.4 shows a comparison between the observed and expected result. 


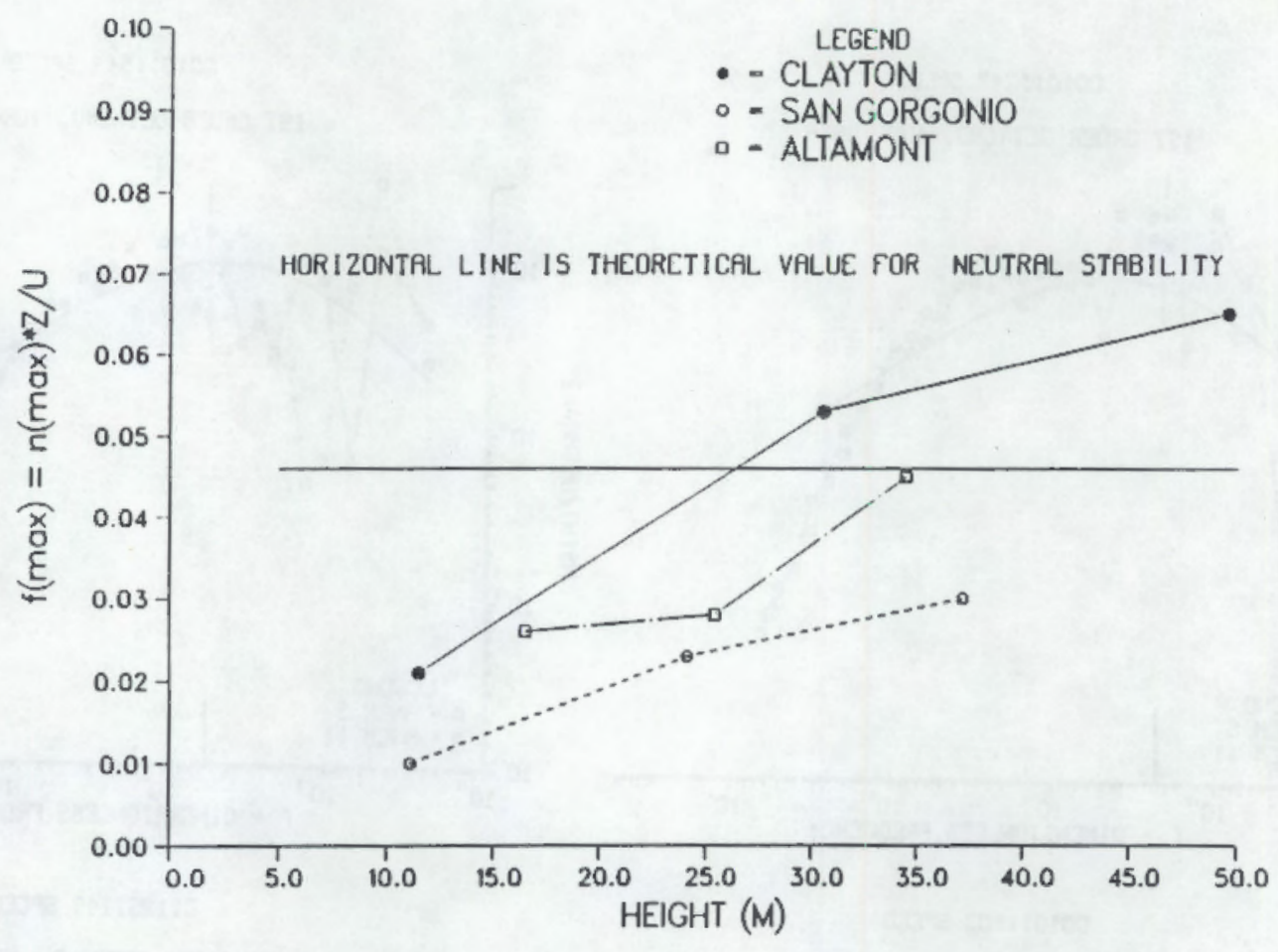

FIGURE 3.4. Observed Values of fmaxu

When the functions in the last two figures are compared to each other, a certain inverse relation is apparent, which suggests that a product, such as $n_{\max }$ times $T$, the total time of the sample, may be a more orderly result. This is shown in Figure 3.5. This result is also the quotient of the integral scale by the scale of maximum energy, $L_{u x} / 1_{\max }$. This turns out to be about one-fifth at $\mathrm{Clayton}$ and somewhat less than that at the two complex terrain sites.

\subsection{RECOMMENDATIONS}

The results shown above do not converge to a model. Evidently, the coefficient $\mathrm{C}$ in $\mathrm{Lux}_{\mathrm{ux}}=\mathrm{CH}$ is height-dependent for a body of data representing a range of stability such as exists during operating conditions. Presumably, the $C$ may also depend on terrain. Because $L_{u x}$ depends on the left side of the spectrum, the basic uncertainty is in the spectrum as it applies to operating conditions. 


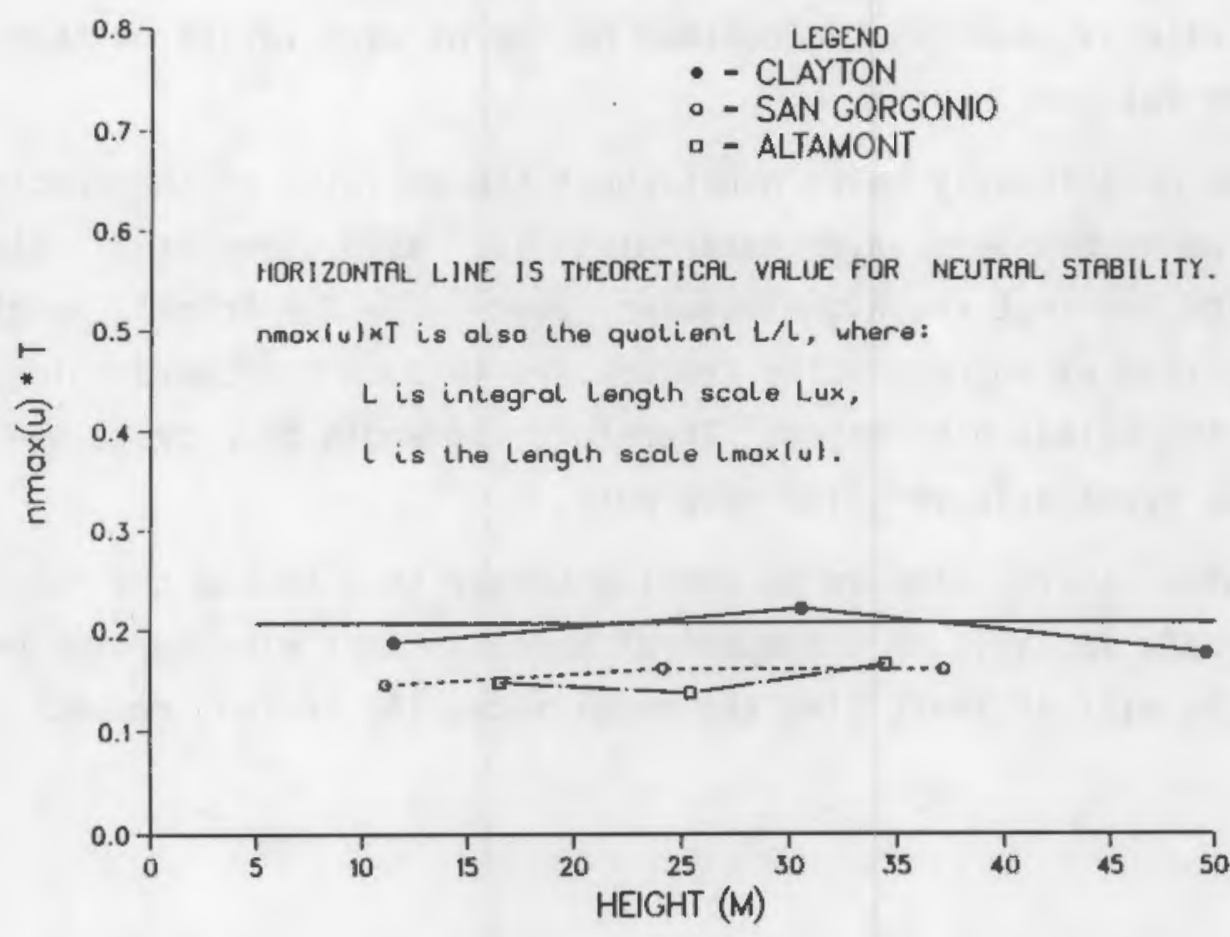

FIGURE 3.5. Quotient of Integral Scale by Scale of Maximum Energy

One recommendation would be to fund a sufficiently comprehensive spectral study at many sites to provide a consensus model of Lux for operating conditions. A basic step would be to reaffirm the spectral gap hypothesis (Vander Hoven 1957). Vander Hoven's spectrum runs over six frequency decades, and shows two peaks, one at 1 cycle per 4 days and the other at 1 cycle per min separated by a comparative gap at intermediate frequencies. Since this spectrum is lowest at frequencies between 1 cycle per 2 hours and 1 cycle per 10 min, this frequency range is called the spectral gap.

This is a concept of the greatest importance because the statistics of turbulence analysis should vary by little when the period of analysis varies from 1 cycle per 2 hours to 1 cycle per $10 \mathrm{~min}$. If this is true, then such turbulence statistics as variance and length scales have a validity based on the intrinsic characteristics of turbulence only. But, if the spectral gap hypothesis is not true, then these statistics depend significantly on the period of the data sample. If so, then for each application, such as wind 
turbine technology, the period of the data sample must be determined by extrinsic criteria, such as the maximum period of wind variation that causes wind turbine fatigue.

One now occasionally hears doubt about the validity of the spectral gap hypothesis among boundary-layer meteorologists. Also, Chan et al. (1983) rightly point out that the high-frequency peak in Vander Hoven's spectrum is much higher than at corresponding frequencies in such micrometeorological spectra as the Kaimal u spectrum. Therefore, it would be nice to see the spectral gap hypothesis verified once more.

Otherwise, there seems to be nothing better than to use the length scale that is already implicit in the spectral model in your wind turbine model. Such a choice will at least give the model integrity in that respect. 


\subsection{SENSITIVITY OF PARAMETERS TO DATA HANDLING CHOICES}

According to the spectral gap theory for atmospheric boundary layer turbulence (Vander Hoven 1957), there is little turbulence energy in those frequencies that are the reciprocals of time periods on the order of 10 min to $1 \mathrm{~h}$. Therefore, when the wind is a relatively stationary process, the observed values of such parameters as variance and length scale for a 10-min data sample should not differ greatly from observed values for extensions of the same sample to 20,30 , or even $60 \mathrm{~min}$. Apparently this is taken for granted in most micrometeorological publications since the authors usually quote one time length for the data samples their analysis is based on.

In this section we show how variance and the two measurable length scales $L_{u x}$ and $\operatorname{Lmax}_{u}$ vary when the length of data sample changes within the spectral gap (or almost so). Also, we show how $L_{u x}$ and the variance change when the detrending polynomial subtracted from each series is increased from the first order to the second order. (First-order detrending is subtracting the bestfitting linear polynomial from the time series. Second-order detrending is subtracting the best-fitting second-order polynomial from the time series.) Figures 4.1 through 4.3 show these variations, using data from three sites. Figure 4.1 is for variance; Figure 4.2 is for Luxi and Figure 4.3 is for Lmaxu.

We see that even though variance is a second-order parameter and length scales are a first-order parameter, the two length scales are both more sensitive to data-handling than is the variance. Note that no representation in Figure 4.1 shows a ratio of observed variances for the same test exceeding 1.5. On the other hand, some of the observed integral length scales show a ratio exceeding 6 to 1 for the same test. This result is expected because the integral length scale depends primarily on the low frequency part of the spectrum more than does the variance, and the low frequency part is the most variable from test to test.

Now consider for a moment only two of the data species in Figure 4.1, 4.2, and 4.3--2048 data with first-order detrend and 4096 data with firstorder detrend. The time spans of 2048 and 4096 data are $512 \mathrm{~s}$ and $1024 \mathrm{~s}$, respectively. If we compute the ratio of the second to the first for each 

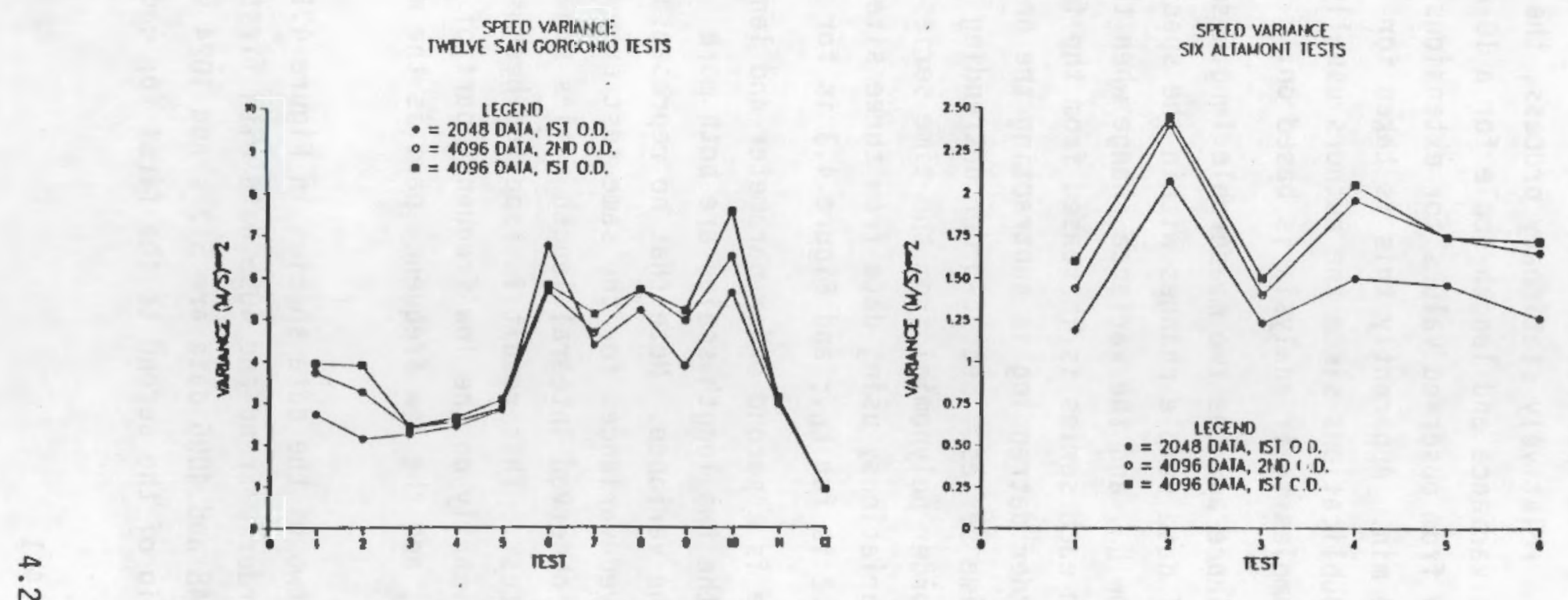

is

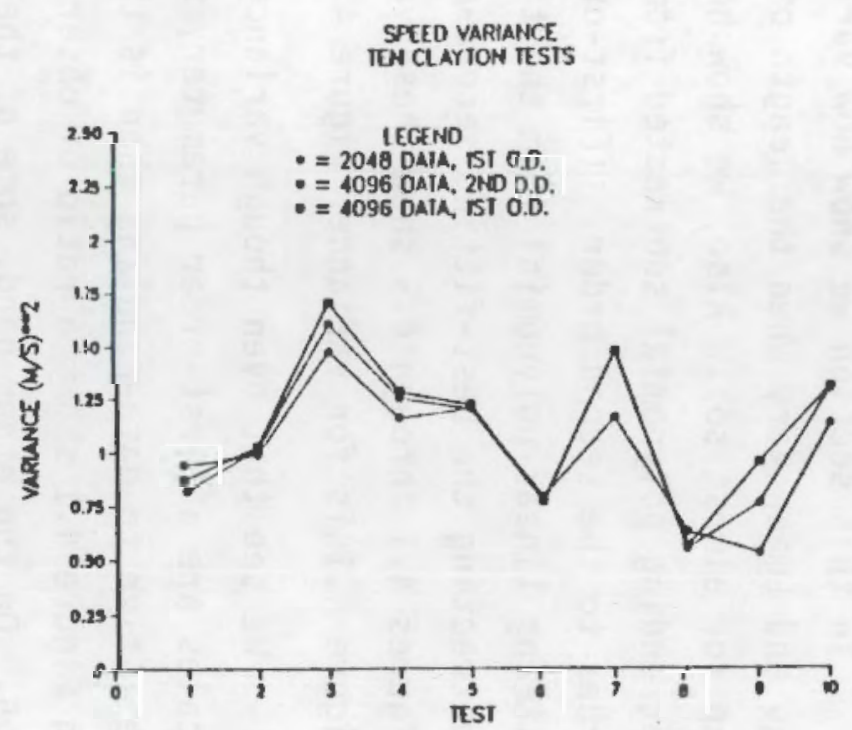

FIGURE 4.1. Change of EUV with Data Handling from Test to Test, Three Sites 

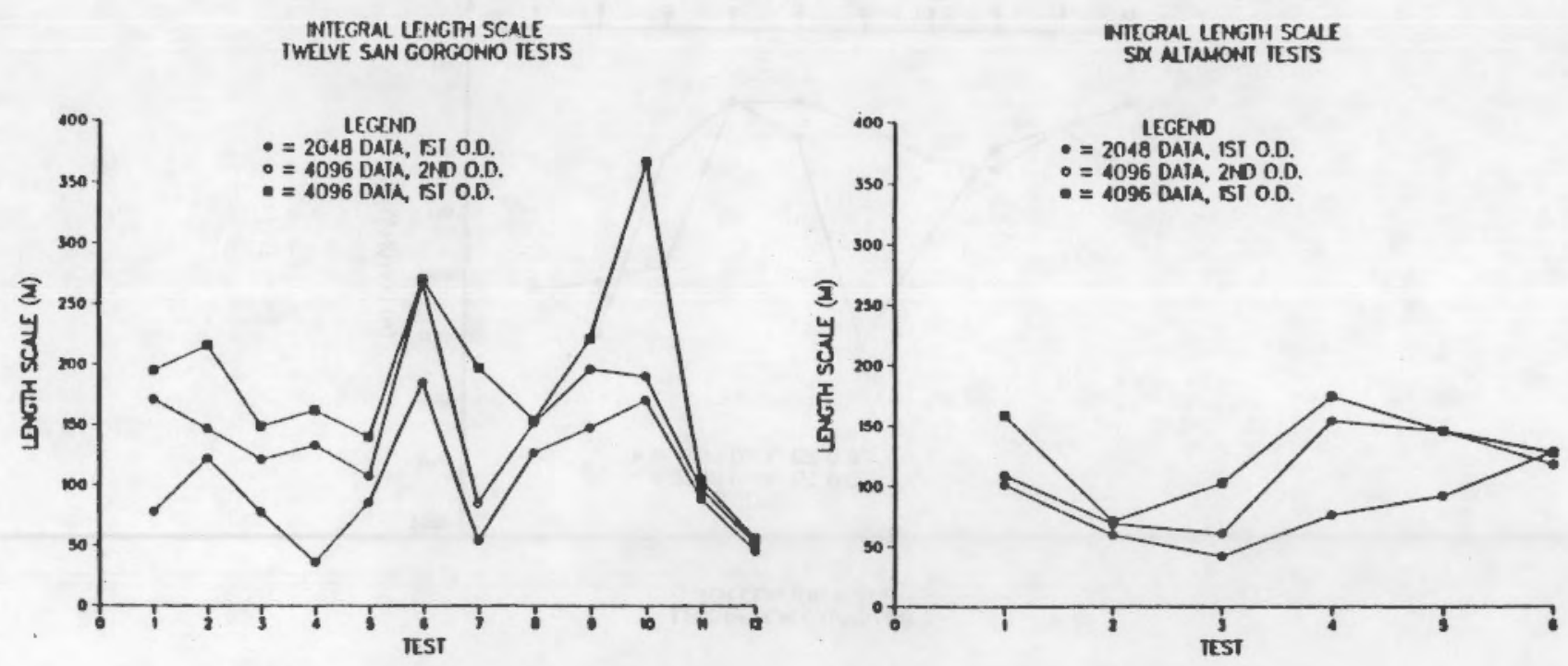

i

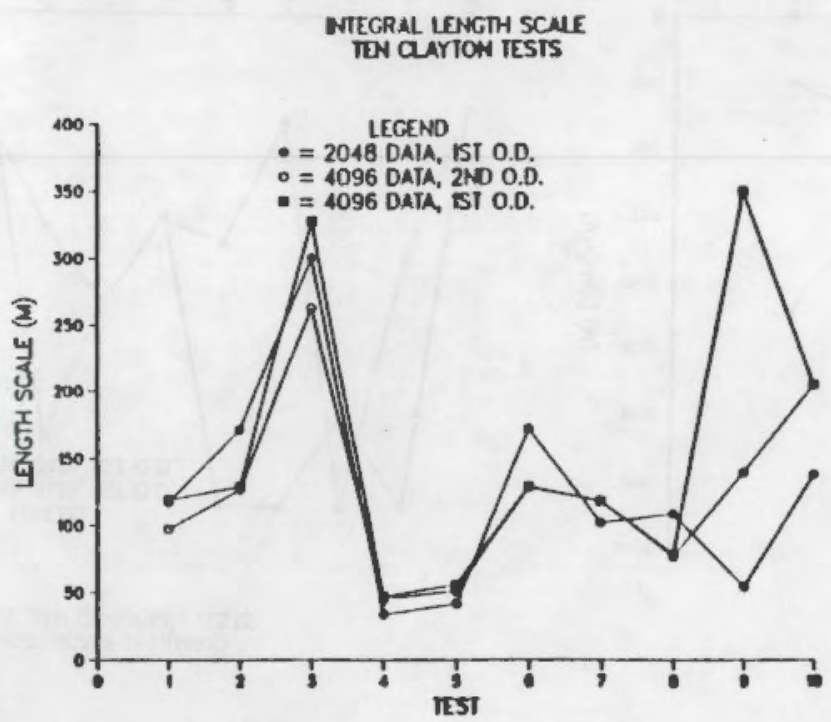

FIGURE 4.2. Change of $L_{u x}$ with Data Handling from Test to Test, Three Sites 

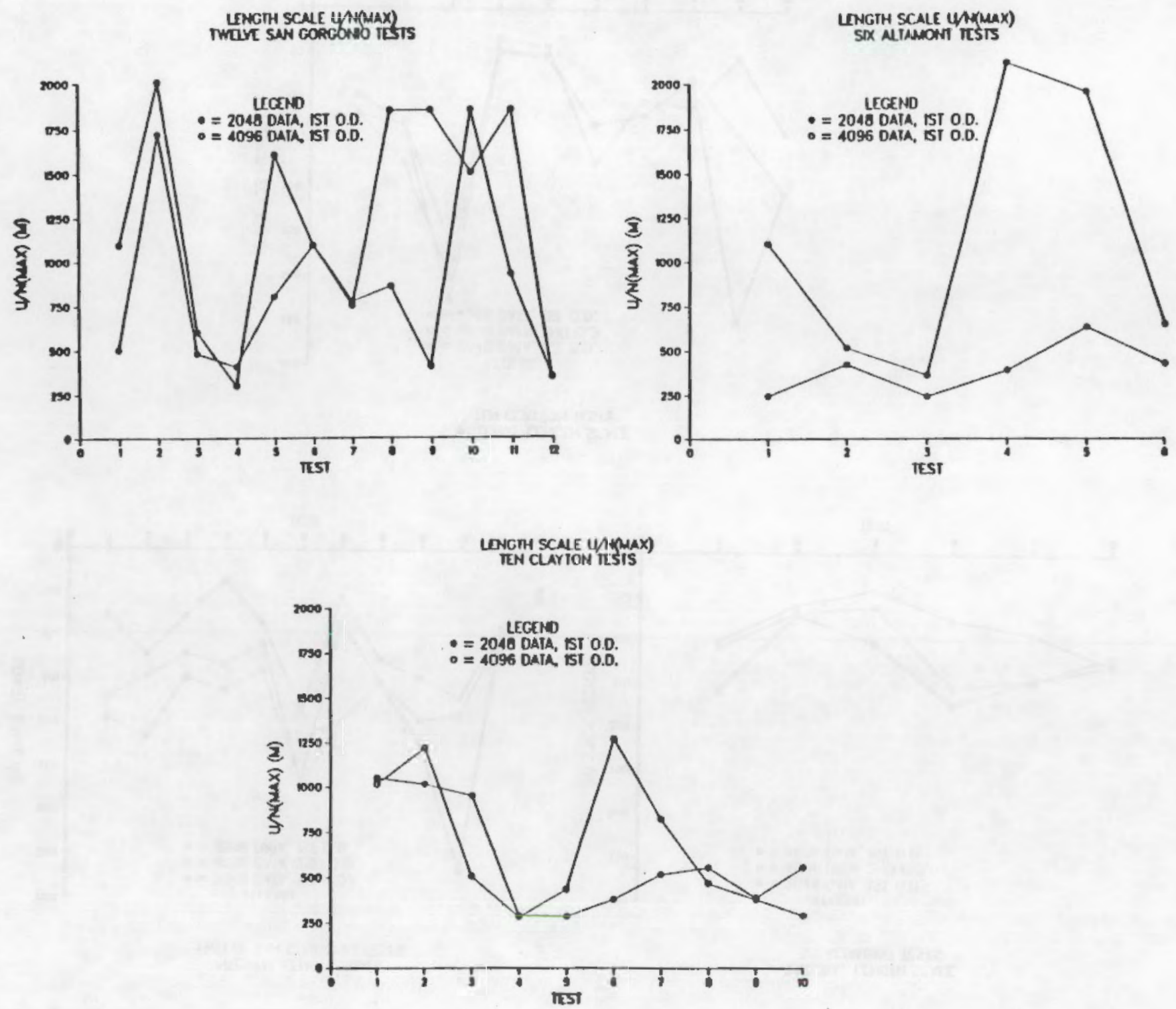

FIGURE 4.3. Change of $\operatorname{Lmax}_{\mathbf{U}}$ with Data Handling from Test to Test, Three Sites 
test shown in the graphs, and then average, we obtain Table 4.1. The table shows that both length scales are more sensitive to arbitrary length of sample than is EUV.

The result certainly shows the need for standardization of data-handling procedures that feed into these types of analyses for wind engineering purposes.

A1l other analys is of Eulerian data in this report is based on samples of 4096 data linearly detrended. The rotational data analyzed in Appendix $C$ were 4096 data per sample and were not detrended.

TABLE 4.1. Mean Ratios Comparing Calculations

Made with 4096 Data to Those Made

with 2048 Data, $\Delta t=0.25 \mathrm{~s}$, 1st 0.0 .

in All Cases

$\begin{array}{ll}\text { EUV } & 1.18 \\ \mathrm{~L}_{\mathrm{ux}} & 1.57 \\ \operatorname{Lmax}_{\mathrm{u}} & 1.49\end{array}$


-

.

• 


\subsection{CONCLUSIONS}

In this report we have examined criteria for estimating the Eulerian variance of the $u$ component of turbulence, EUV, and the longitudinal and lateral length scales of the same component, $L_{u x}$ and $L_{u y}$. We assert that a probability distribution of EUV, rather than just an average value of it, is the required descriptor--this because of the nonlinearity of fatigue response in wind turbines. Such a probability description depends physically on the joint probability distribution of mean wind speed, upwind surface roughness, and stability. In view of the difficulties in determining all this, we suggest that measurement is the indispensible part of any estimation of onsite EUV. Such estimates then should be checked by reference to simple theory, such as the equation

$$
\sigma_{u^{2}}=1.2\left[\bar{U}(H) / \ln \left(H / z_{0}\right)\right]^{2}
$$

which provides EUV estimate at neutral stability for a given mean wind speed, the height of measurement and an estimate of surface roughness. Onsite surface roughness estimate is usually made from a table, such as Table 2.1. The weakness in this application is that the surface features of the site may be complex enough that the table cannot be used with confidence. Recommendations for carrying out the measurement program are given in Subsections 2.3 and 2.6.

We find that the integral length scale $L_{u x}$, as observed from analys is of data taken under wind energy programs, does not conform to the theory that is implicit in the simple boundary-layer spectral models for neutral stability. According to the spectral models, Lux should be a constant multiple of height, say 4 to 6 times the height, but analysis of data taken under typical operating conditions for wind turbines shows $L_{u x}$ increasing according to the 0.2 power.

Also $L_{u x}$ is more sensitive than is variance to arbitrary options in data management, which include length of sample, discretization interval, and order of detrend used before analysis. We know less about $L_{u y}$, and rely on a suggestion by Counihan (1975) that $L_{u y}$ is about $0.4 L_{u x}$. Using spectral criteria and Counihan's suggestion, we come up with weak suggestions to the effect that 


$$
\begin{aligned}
& L_{u x}=4.6 \mathrm{z} \\
& L_{u y}=1.8 \mathrm{z} .
\end{aligned}
$$

Both EUV and Lux may be calculated from any current spectral model of u-component turbulence. EUV depends on the entire spectrum; $L_{u x}$ depends on the placement of the low-frequency siope, as is best seen in $\mathrm{nS}_{\mathrm{u}}(n)$ spectra. The basic trouble in modeling both parameters is uncertainty about the placement of the low-frequency side to represent an average value for the range of stability that prevails during operating conditions for wind turbines. This uncertainty is particularly exacerbated by the fact that the low-frequency side of $\mathrm{nS}_{\mathrm{u}}(\mathrm{n})$ shifts discontinuously from its position for neutral stability to its position for the least measurable degree of unstable stability.

An attempt is made to model the harmonic spike variances of the spectrum of turbulence at a rotating point in Appendix $C$. We conclude that a sufficient model, producing average values of the quotient of the harmonic spike variances by EUV, depends principally on having a model for the lateral integral length scale of $u, L_{u y}$. The low confidence attending any model we have for this parameter is the reason for relegating this part of our investigations to appendix status. However, the models of $L_{u x}$ and $L_{u y}$ quoted above as Equations (3.18) and (3.23) are the best we can provide at this time. 


\subsection{REFERENCES}

Chan, S. M., D. Curtice, and S.-K. Chang. 1983. Methods for Wind Turbine Dynamic Analysis. AP-3259 Research Project 1977-1, Systems Control, Inc., Palo Alto, California.

Counihan, J. 1975. "Review Paper - Adiabatic Atmospheric Boundary Layers: A Review and Analysis of Data from the Period 1880-1972." Atmospheric Environment 9:871-905.

Frost, W., B. H. Long, and R. E. Turner. 1978. Engineering Handbook on the Atmospheric Environmental Guidelines for Use in Wind Turbine Generator Development. NASA Technical Paper 1359, Marshall Space Flight Center, Huntsvilie, Alabama.

Hojstrup, J. 1982. "Velocity Spectra in the Unstable Planetary Boundary Layer." Journal of the Atmospheric Sciences 39:2239-2248.

Horst, T. W. 1973. "Corrections for Response Errors in a Three-Component Propeller Anemometer." Journal of Applied Meteorology 12:716-725.

Izumi, Y. 1971. Kansas 1968 Field Program Data Report. AFCRL-72-0041, Air Force Cambridge Research Laboratories, Bedford, Massachusetts.

Justus, C. G., W. R. Hargraves, and A. Yalcin. 1976. "Nationwide Assessment of Potential Output from Wind-Powered Generators." Journal of Applied Meteorology 15:673-678.

Kaimal, J. C. 1973. "Turbulence Spectra, Length Scales and Structure Parameters in the Stable Surface Layer." Boundary-Layer Meteorology 4:289-309.

Kaimal, J. C., J. C. Wyngaard, Y. Izumi, and 0. D. Cote. 1972. "Spectral Characteristics of Surface Layer Turbulence." Quarterly Journal of the Royal Meteorological Society 98:563-589.

Korre1, A., H. A. Panofsky, and R. D. Rossi. 1982. "Wind Profiles at the Boulder Tower." Boundary Layer Meteorology 22:295-312.

Panofsky, H. A., and J. A. Dutton. 1984. Atmospheric Turbulence. John Wiley \& Sons, New York.

Powel1, D. C., and J. R. Connell, 1986. A Model for Simulating Rotational Data for Wind Turbine Applications. PNL-5857, Pacific Northwest Laboratory, Richland, Washington.

Powell, D. C., J. R. Connell, and R. L. George. 1985. Verification of Theoretically Computed Spectra for a Point Rotating in a Vertical Plane. PNL-5440, Pacific Northwest Laboratory, Richland, Washington. 
Vander Hoven, I. 1957. "Power Spectrum of Horizontal Wind Speed in the Frequency Range of 0.0007 to 900 Cycles Per Hour." Journal of Meteorology $14: 160-164$.

Wylie, C. R., Jr. 1966. Advanced Engineering Mathematics. Third Edition, McGraw-Hil1 Book Company, New York. 


\section{APPENDIX A}

\section{COMPARISON OF OBSERVED AND CALCULATED VARIANCES}




\section{APPENDIX A}

COMPARISON OF OBSERVED AND CALCULATED VARIANCES

A.1 AFCRL DATA - HEIGHT AND ROUGHNESS LENGTH, 22.63, 0.024 METERS

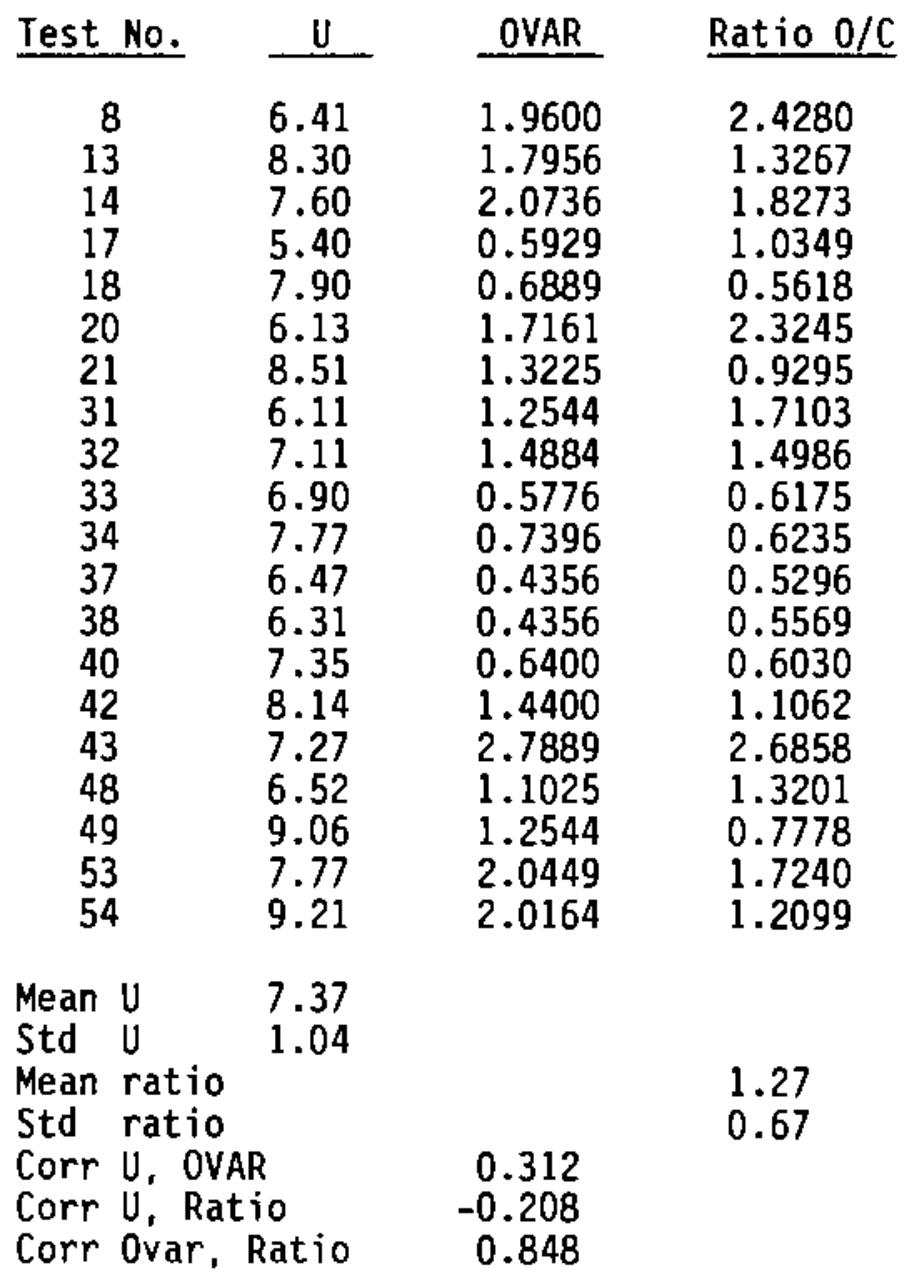


A.2 CLAYTON DATA - HEIGHT AND ROUGHNESS LENGTH, $30.5,0.005$ METERS

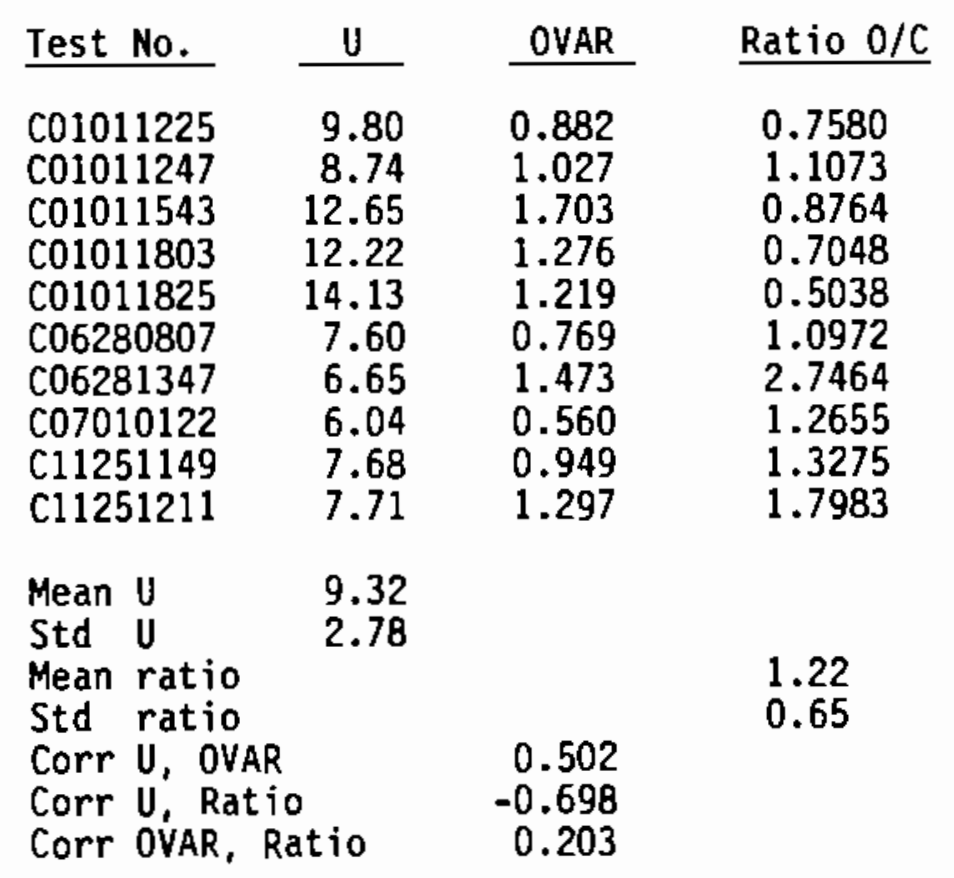




\section{APPENDIX B}

EXPLANATION OF FRICTION VELOCITY, $u_{+,}$AND RELATED CONCEPTS 
APPENDIX B

\section{EXPLANATION OF FRICTION VELOCITY, $u_{ \pm,}$AND RELATED CONCEPTS}

Recognizing that turbulence owes much to external effects that impinge on the flow of fluids, experts in micrometeorology and fluid mechanics have defined such things as scaling velocities, scaling lengths, and scaling temperatures that are all composed of physical quantities other than the scaling quantity on the left side of the equation. There are two essential problems in defining such a scaling quantity. First the physical quantities on the right side must be selected from penetrating insight into the essential physical situation that is creating turbulence, and second each quantity on the right must have the correct power so that the scaling quantity on the left has the correct and only admissible physical dimension.

Now, such a scaling velocity is called $u_{\star}$. Once the physical assumptions at its origin and at the mathematical process of its formulation are understood, the quantity should no longer have the unfamiliar, unfriendly character that many non-meteorologists assign it when they run across it.

Recall the fundamental physical principle, that turbulence results from externally imposed conditions imposed on the flow. $u_{*}$ is a scaling velocity based on the assumption that turbulence in the atmospheric boundary layer is caused by the stress of fluid retardation at the surface, with its inherent roughness, acting on fluid of a given density. This assumption excludes effects from heat flux, positive or negative. Now the physical dimensions of stress are

$$
\text { Dimensions of stress }=\text { Mass } /\left(\text { Length } \times \text { time }^{2}\right) \text {. }
$$

Another way to write the same thing is

$$
\text { Dimensions of stress }=\text { Mass } / \text { Length } 3 \times(\text { Length } / \text { time })^{2},
$$


which is to say the dimensions of stress are those of density multiplied by the square of velocity.

Since the density of a fluid has something to do with how much turbulence velocity can be created by a given amount of stress, density is also in the physical equation for $u_{\star}$. Applying mathematics to get an expression for velocity from stress and density, we come up with

$$
u_{\star}^{2}=\text { surface stress/surface air density. }
$$

The magnitude of the stress obviously depends on the mean wind speed at some reference level not far above the surface. The equation of this relationship is the logarithmic wind equation, which may be written as

$$
u_{\star}=0.4 \bar{U}(z) / \ln \left(z_{2} / z_{0}\right)
$$

when $z$ is at a suitable reference level, such as $30 \mathrm{~m}$. According to surface layer theory, $z$ may be anywhere in the surface layer, which may be conservatively estimated to extend from $10 \mathrm{~m}$ to $50 \mathrm{~m}$. The 0.4 is von Karman's constant, which is variously given as 0.35 to 0.41 .

Note this range of uncertainty, which is $15 \%$ of 0.4 . This is for a first power relationship. If you extrapolate this uncertainty to the second power, that of variance, you get $32 \%$. No estimates derived from theoretical means can escape this kind of uncertainty.

Incidentally, Equation (B.2) gives another definition of $z 0$. It is the zero extrapolation height of the logarithmic wind equation. We call it an extrapolation point because the logarithmic wind equation does not describe the wind for $z$ less than one or two orders of magnitude greater than $z_{0}$.

Having properly introduced $u_{\star}$, what are we going to do with it? The model of variance we are going to recommend is based on a summary by Panofsky and Dutton (1984) of ratios various investigators have found between $\sigma_{u}$ and $u_{\star}$. Their surmary equation is

$$
\sigma_{u}=2.39 u_{\star}
$$


Now, if we combine this equation with Equation (B.2) and if we remember that $\sigma_{\mathrm{u}}$ is the square root of variance, we obtain:

$$
\sigma_{u}{ }^{2}=0.92\left[\frac{\tilde{U}(H)}{\ln \left(H / z_{0}\right)}\right]^{2}
$$

where $H$ is the height of interest (hopefully between 10 and 50 or so $\mathrm{m}$ ) and $z_{0}$ is the surface roughness length. In this report EUV and $\sigma_{\mathrm{u}}{ }^{2}$ are synonymous. This equation applies only for neutral stability. The numerator of this equation is often simplified to 1.0 since the 0.92 implies more precise knowledge than we have. The final equation we recommend will be of this form but with the numerical coefficient altered to reflect the bias we find when this model is applied to data taken at operational wind speeds over a range of stabilities.

For the unstable atmosphere the variance equation needs additional terms to quantify the degree of instability. The required measurements would usually be outside the scope of wind engineering programs. Two more lengths must be calculated to model the unstable atmosphere, and both are less tractable to evaluate than $z 0$. One of these lengths requires two precise calculations of two turbulence correlations that apply to the wind at the location of an anemometer. An expensive instrument, such as a sonic anemometer, in almost perfect vertical alignment, is required to make sufficiently precise measurements. The other length is the height of the layer throughout which relatively unrestricted mixing takes place. Since the height is typically 500 to $2000 \mathrm{~m}$, remote sensing equipment is required. These things we leave out of our simple model. 
APPENDIX C

ROTATIONAL-EULERIAN RELATIONS, MODELED AND OBSERVED 


\section{ROTATIONAL-EULERIAN RELATIONS, MODELED AND OBSERVED}

In the Introduction the harmonic spike variances, HSVs, of the spectrum of rotational turbulence were mentioned. We wish to model these as a function of EUV, or at least make such an attempt and explain the caveats. To this end we first consider the wind as it occurs at a point describing a circle in a vertical plane as would a point on the rotor of a horizontal-axis wind turbine. The spectrum of wind at such a point, from Clayton data analysis, is shown in Figure C.1. Such a spectrum will have half as many harmonic spikes as there are anemometers in the array, if we count the half spike ending with the Nyquist frequency, which is the reciprocal of twice the sampling interval.

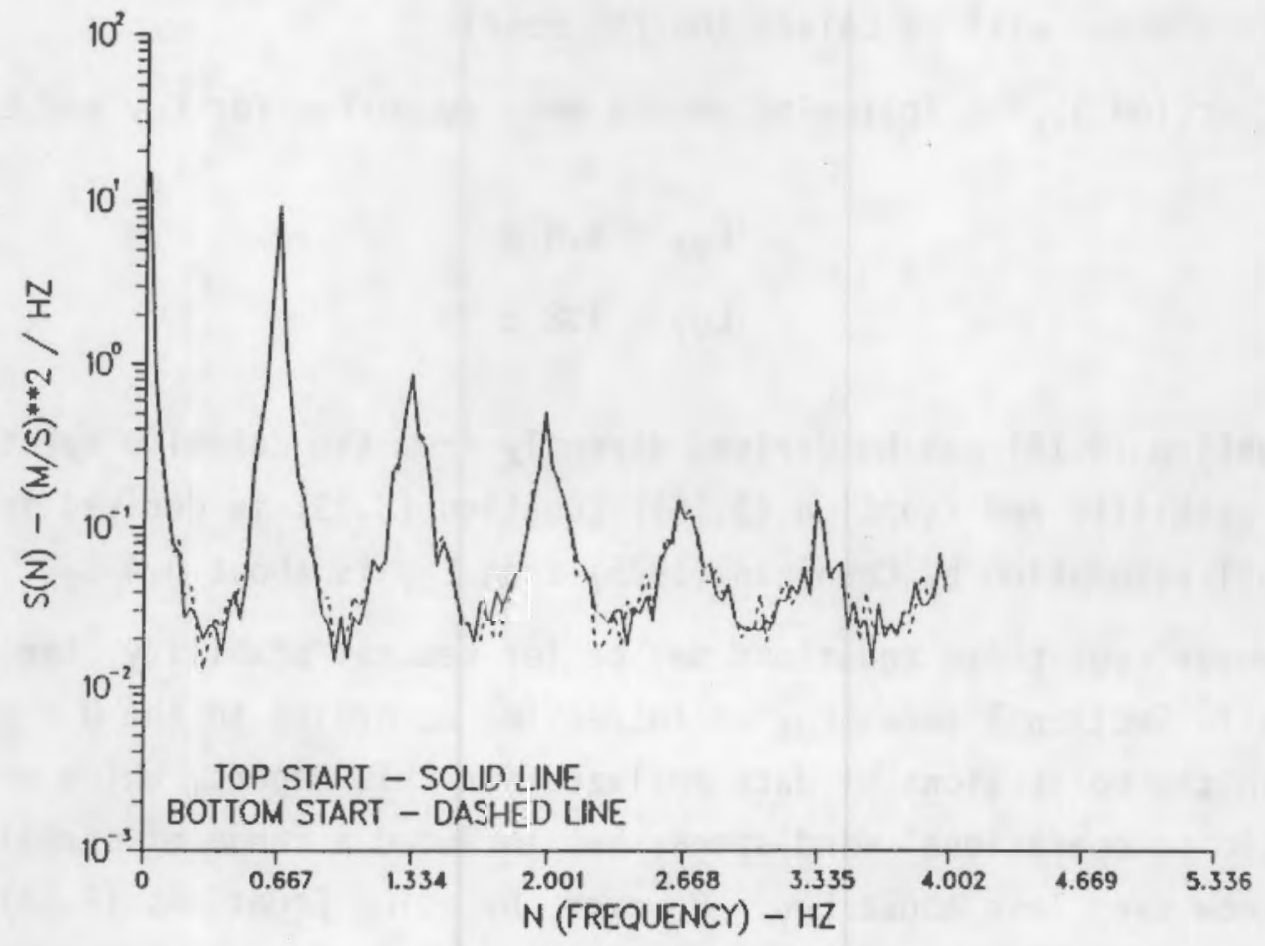

FIGURE C.1. $\quad S(n)$ Spectrum of Rotational wind Speed Data 
The central frequency of the 1P spike is at $0.667 \mathrm{~Hz}$. Let us call this frequency $n(0)$ for use in the equation that follows. This equation expresses the spectral integration necessary to obtain the variances of the harmonic spikes in the figure. For the harmonics 1P, 2P, etc., let us generalize and define the HSV for the kth harmonic by

$$
\begin{aligned}
H S V(k P) & =\int_{k-0.5 n(0)}^{k+0.5 n(0)} S(n) d n, \\
k & =1,2,3, \ldots \ldots
\end{aligned}
$$

Ratios between the HSVs and EUV may be estimated using the model described by Powell and Connell (1986). The basic theory of this model (Connell 1980) was extended by Powell and Connell (1986) so that the original equation of the model is an autocorrelation function that includes a rotational feature and requires both length scales mentioned in Section $3, L_{u x}$ and Luy, as parameters. This model will be called the PNL model.

In Section 3, the following models were suggested for $L_{u x}$ and $L_{u y}$.

$$
\begin{aligned}
& L_{u x}=4.6 \mathrm{z} \\
& L_{u y}=1.8 \mathrm{z}
\end{aligned}
$$

Equation (3.18) can be derived directly from the Kaimal u spectrum for neutral stability and Equation (3.16); Equation (3.23) is derived from the additional assumption by Counihan (1975) that Luy is about 0.4 Lux.

However true these equations may be for neutral stability, the data analysis in Section 3 shows Lux as increasing according to the 0.2 power of height in the collections of data analyzed for this report, which were restricted to operational wind speeds but included a range of stability. And we know even less about Luy. However, by using Equations (3.18) and (3.23), we were able to get surprisingly good comparisons between the HSVs as modeled and as observed by analyzing data from the Clayton VPA, when the HSVs were defined as representing contributions from turbulence, only. This last 
distinction is explained below. Therefore, we have attempted some generalization, without losing sight of the caveats, as is explained below.

This part has additional conceptual complications because the suggested models are in terms of dimensionless variables that incorporate both wind and machine parameters. Therefore, numerous definitions were required to make the writing easier. We were tempted to make more definitions but refrained, because we realize that each new definition the reader has to remember will make the comprehension just that much harder. And the distinctions between some of the definitions are fine enough that at some points the reader may have to stop and review in order to keep these ideas from getting tangled in his or her head. Now if you the reader, find at such a point that your mind has been "blown" because you have encountered one definition too many, you will have to decide either to give up (which may be a good decision) or to go back and try it again. Good luck!

\section{C.1 DEFINITIONS}

In order to make an analytical model of the HSVs we need dimensionless versions. At this point it is advantageous to use the usual custom in turbulence analysis of dividing the total wind into mean wind and turbulence components. However in the case of rotational data, the mean wind that is subtracted from the total wind should be a function of position on the rotational circle. For example, theoretically at neutral stability, the mean wind on the circle would be given by the logarithmic wind equation, which may be obtained by rearranging Equation (B.2) to read

$$
U(z)=2.5 u_{\star} \ln \left(z / z_{0}\right)
$$

The HSVs of Equation (C.1) may be divided as follows:

$\mathrm{HSV}(\mathrm{kP})$, total wind

$H S V(K P)$, turbulence only

HSV (KP), mean wind only . 
We find that the difference between the first two is significant at $1 P$, only. That is,

$$
\begin{gathered}
H S V(k P) \text {, total wind } \approx H S V(k P) \text {, turbulence } \\
\qquad k=2,3 \ldots \ldots
\end{gathered}
$$

\section{C.2 DIMENSIONLESS ANALYSIS}

Let us consider such a dimensionless quotient as

$$
\mathrm{HSV}(\mathrm{kP}) \text {, turbulence only/EUV, } k=1,2, \ldots
$$

According to the PNL model this quotient is a function of two dimensionless variables that were previously defined by Powell and Connell (1986). They are

$$
\begin{aligned}
& \alpha=R / L_{u y} \\
& \beta=\bar{U} /\left[\begin{array}{ll}
n(0) & \left.L_{u x}\right] .
\end{array}\right.
\end{aligned}
$$

Therefore, we can write the dimensionless equation

$$
\operatorname{HSV}(\mathrm{kP}) \text {, turbulence only/EUV }=\phi_{1}(\alpha, \beta) .
$$

\section{3 COMPARISON OF OBSERVED AND MODELED RESULTS, TURBULENCE ONLY}

A series of PNL model runs indicated that when $\alpha$ and $\beta$ are varied about values that are typical for the Clayton VPA, using Equations (3.18) and (3.23) to evaluate $L_{u x}$ and $L_{u y}$, respectively, the quantity on the left of Equation (C.5) is strongly a function of $a$ and very weakly a function of $\beta$. Therefore, we exhibit Equation (C.5) as a function of $\alpha$ in Figure C.2, which was derived by running the PNL model. 


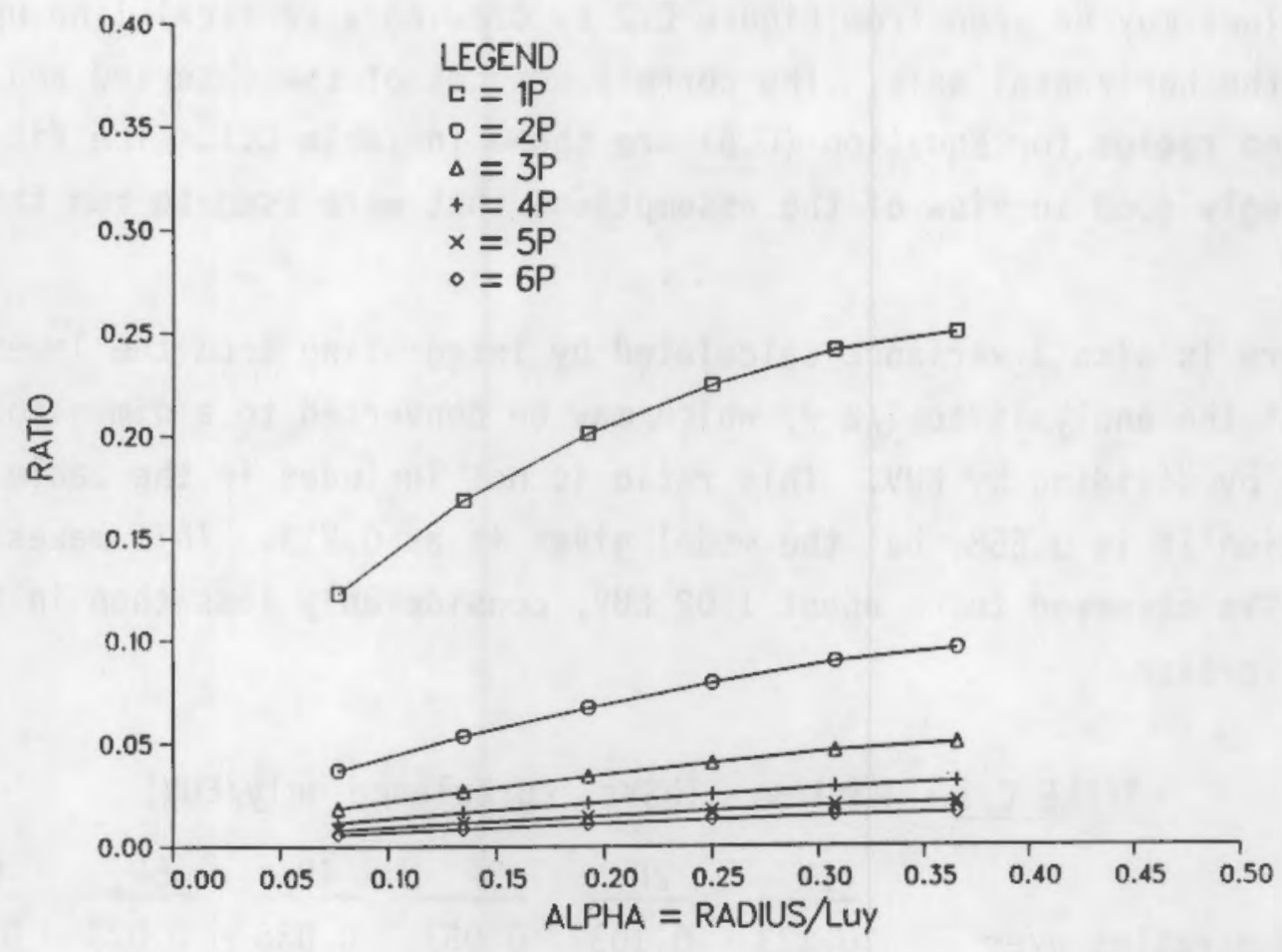

FIGURE C.2. Ratios of HSVs, Turbulence Only, to EUV

The values in this figure agree well with observed values from Clayton data analysis, in spite of uncertainty about the length scales. The independent variables of the Clayton data analysis are:

$$
\begin{aligned}
H & =30.5 \mathrm{~m} \\
\mathrm{R} & =19.0 \mathrm{~m} \\
\mathrm{n}(0) & =0.667 \mathrm{~Hz} \\
\mathrm{z} 0 & =0.005 \mathrm{~m} .
\end{aligned}
$$

For each of $10 \mathrm{Clayton}$ tests (conducted in January, June, July and November, 1981-1982) the ratios of these harmonic spike variances to the observed EUV was calculated. This is the quantity on the left of Equation (C.5). Then these 10 ratios were averaged for each of the six Ps. These averages are then compared to the predicted result for the assumed values of $a$, which was

$$
a(\text { assumed })=19.0 /(1.8 \times 30.5)=0.35 \text {. }
$$


These values may be seen from Figure $C .2$ by drawing a vertical line up from 0.35 on the horizontal axis. The correspondences of the observed and calculated ratios for Equation (C.5) are shown in Table C.1. The fit is surprisingly good in view of the assumptions that were used to run the PNL model.

There is also a variance calculated by integrating from the lowest frequency of the analysis to $1 / 2 \mathrm{P}$, which may be converted to a dimensionless variance by dividing by EUV. This ratio is not included in the table. From observation it is 0.558 , but the model gives it as 0.213 . This makes the sum of the HSVs observed to be about 1.02 EUV, considerably less than in the modeled version.

TABLE C.1. Ratios: (HSVs, turbulence only/EUV)

$\begin{array}{llllllll}\begin{array}{c}\text { Average ratios over } \\ 10 \text { tests, observed }\end{array} & \frac{1 P}{0.223} & \frac{2 P}{0.103} & \frac{3 P}{0.057} & \frac{4 P}{0.036} & \frac{5 P}{0.028} & \frac{6 P}{0.013} \\ \begin{array}{c}\text { Ratios calculated } \\ \text { using PNL model }\end{array} & 0.253 & 0.099 & 0.052 & 0.032 & 0.023 & 0.016 \\ & & & & & & \end{array}$

\section{C.4 COMPARISON OF OBSERVED RESULTS, TOTAL WIND VERSUS TURBULENCE ONLY}

Recall now that the HSVs in the numerator of the ratios exhibited by Figure C.2 are for turbulence only. Thus, the practical value of Figure C.2 is diminished by the fact that there is still a significant contribution to the harmonic spike variance at $1 \mathrm{P}$ that is unaccounted for. This contribution comes from variation of the mean wind with height. Since the total variation depends on the radius of rotation, this contribution to HSV(1P) must include the radius $\mathrm{R}$ in any normalization. According to the theory of the PNL model, the normalization is

$$
\text { HSV (1P), mean wind only/U(H) } 2=\phi_{2}\left(\mathrm{R} / \mathrm{H}, \mathrm{H} / \mathrm{zO}_{\mathrm{O}}\right) \text {. }
$$

Running the model on a matrix of values of $R / H$ and $H / Z_{O}$ indicates that $R / H$ is much more important than $\mathrm{H} / \mathrm{zO}$. 
On the average, the observed values of the quantity on the left are about 1.7 the values obtained from the model. Therefore, we do not attempt to generalize by using modeled results.

We tried another approach. We laid the model aside and looked strictly at observed results. Consider the ratio (dimensionless, of course)

$H S V(k P)$, total wind/HSP $(k P)$, turbulence only, $k=1,2 \ldots 6$.

Table C.2, below, lists these ratios as they were obtained by first calculating the ratio for each spike for each of $10 \mathrm{clayton}$ tests and then averaging these ratios. The table shows that the difference between the HSVs of total wind and those of turbulence only is important only at $1 P$ in this analysis. At 1P from these data, we find that the harmonic spike variance for total wind is about three times that for turbulence only. This is higher than the ratio given by Powell et al. (1985) on the basis of analysis of a smaller number of tests. The ratio at $1 \mathrm{P}$ varied from 1.3 to 7.1 among the 10 tests represented in the averaging produced in the table.

TABLE C.2. Ratios: (HSV, total wind/HSV, turbulence only)

$\begin{array}{lllllll}\begin{array}{c}\text { Average ratios over } \\ 10 \text { tests, observed }\end{array} & \frac{1 P}{3.17} & \frac{2 P}{1.06} & \frac{3 P}{1.08} & \frac{4 P}{1.02} & \frac{5 P}{1.07} & \frac{6 P}{1.00}\end{array}$

\section{C.5. INTERPOLATION OR EXTRAPOLATION OF THE ABOVE COMPARISON TO DATA} FOR OTHER SITES

The usefulness of the above materials depends on how much confidence we can place in them and any extrapolations made of them to characterize rotational turbulence at other sites. What we actually have at this point consists of:

1. Figure C.2, which models the HSVs for turbulence only on EUV. The model is the ratio of the two, and is found to be a strong function of one variable, $R / L_{u y}$. The problem is lack of confidence in the model of Luy. Equation (3.23) proposed in this report. 
2. A statement that the HSVs for the total wind differ significantly from those for turbulence only at $1 \mathrm{P}$, only. This statement we make with higher confidence provided that the ratio of blade radius to height, $\mathrm{R} / \mathrm{H}$, does not exceed 0.8 .

3. An illustration from analysis of Clayton data showing that HSV(1P) for total wind is about three times HSV(1P) for turbulence only. However, no basis was given for extrapolating this result to other sites.

To examine the feasibility of so extrapolating, let us make one more (and only one more) definition. The above ratio can be written

$$
\mathrm{DH}(1 \mathrm{P})=\mathrm{HSV}(1 \mathrm{P}) \text {, total wind/HSP(1P), turbulence only. }
$$

Let us assume that $\mathrm{DH}(1 \mathrm{P})$ is principally a function of $R / H$, the ratio of blade radius to height. We are proposing at this point:

$$
\begin{aligned}
& \mathrm{DH}(1 \mathrm{P}) \text { - dependent variable } \\
& \mathrm{R} / \mathrm{H} \text { - associated independent variable. }
\end{aligned}
$$

Physically this seems to make sense. One can easily see that as the blade radius and this ratio approach zero, $\mathrm{DH}$ (1P) must approach unity. Now for the Clayton site the radius was $19.0 \mathrm{~m}$, and the height was $30.5 \mathrm{~m}$. Therefore, the ratio $\mathrm{R} / \mathrm{H}$ is 0.62 , and when the HSV ratio in question is given as 3.17 in Table C.2, the associated independent variable, $R / H$, is 0.62 . We offer some tempting extrapolation criteria, which are summarized below in Table C.3. Mathematically one can easily interpolate and extrapolate from this table.

TABLE C.3. Tempting Extrapolation Criteria for DH(1P) As a Function of $\mathrm{R} / \mathrm{H}$

$\begin{array}{ll}\frac{\mathrm{R} / \mathrm{H}}{0.0} & \frac{\mathrm{DH}(1 \mathrm{P})}{1.0 \text { anywhere }} \\ 0.62 & 3.2 \text { Clayton }\end{array}$


However, there are two caveats to using such a result. One is that, since stability is ignored, the result can be applied only to an average of data, and only if the average stability of two sites is about the same. This may be true if the maximum winds at each site occur at the same time of day. Stability at two sites will not be the same if strong winds occur at one site at night and at the other site in the daytime.

The other caveat is that $\mathrm{R} / \mathrm{H}$ may not be the only important independent variable that affects the extrapolation. Yes, we assumed that it is, a few lines above, but there are actually four independent variables that could affect $D H(1 P)$. These are $\alpha$ and $\beta$ as defined above, $R / H$ and $H / z O$. By repeatedly running the PNL model on appropriate matrices of values for the independent variables, we can hypothesize which of the independent variables are really dominant in determining the ratios we are interested in.

At this point some review may well be in order. We recall the three types of HSV given above:

$$
\begin{aligned}
& \text { HSV (kP), total wind } \\
& \text { HSV (kP), turbulence only } \\
& \text { HSV (kP), mean wind only. }
\end{aligned}
$$

From these we have deduced three dimensionless variables to model

$$
\begin{aligned}
& \text { HSV }(k P) \text {, mean wind only/U(H) } \\
& \text { HSV }(k P) \text {, turbulence only/EUV } \\
& \text { HSV(1P), total wind/HSV(1P), turbulence only - called DH(1P). }
\end{aligned}
$$

\begin{tabular}{|c|c|c|}
\hline Model & $\begin{array}{c}\text { Complete Dmls. } \\
\text { Variables } \\
\end{array}$ & $\begin{array}{c}\text { Dominant Dmls. } \\
\text { Variables }\end{array}$ \\
\hline $\mathrm{HSV}(\mathrm{kP})$, mean wind only/U(H)2 & $\mathrm{R} / \mathrm{H}, \mathrm{H} / \mathrm{ZO}_{\mathrm{O}}$ & $\mathrm{R} / \mathrm{H}$ \\
\hline HSV(kP), turbulence only, /EUV & $a, \beta$ & $a$ \\
\hline $\mathrm{DH}(1 \mathrm{P})$ & $\mathrm{R} / \mathrm{H}, \mathrm{H} / \mathrm{zO}, a, \beta$ & $\mathrm{R} / \mathrm{H}$ \\
\hline
\end{tabular}

By exercise of the PNL model, we find that the complete list of variables for each, and the dominant variables are as given in Table C.4. In each case the

TABLE C.4. Complete List of Dimensionless Variables and Dominant Variables for Proposed Dimensionless Models of HSVS 
dominance of the one dimensionless variable is great enough that the variable could also be called the significant dimensionless variable.

Since $R / H$ turns out to be the significant dimensionless variable governing the ratio of [HSV(1P), total wind/HSV(1P), turbulence only], use of the numbers in Table C.3 to interpolate or extrapolate this ratio to values of $R / H$ other those in the table seems like a justifiable first approximation.

And, according to the PNL model and the above results, the only major stumbling block to estimating the HSVs once the EUV is estimated or known, is estimating Luy.

\section{C.6 REFERENCES}

Connel1, J. R. 1980. Turbulence Spectrum Observed by a Fast-Rotating Wind

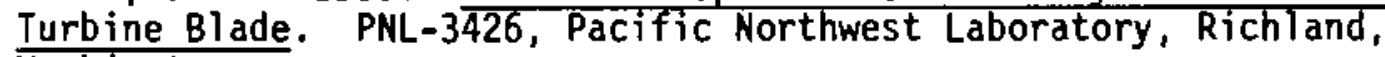
Washington.

Powell, D. C., and J. R. Connell. 1986. A Model for Simulating Rotational Data for Wind Turbine Applications. PNL-5857, Pacific Northwest Laboratory, Richland, Washington. 
APPENDIX D

LINEAR AND QUADRATIC DETRENDING ROUTINE 
APPENDIX D

\section{LINEAR AND QUADRATIC DETRENDING ROUTINE}

In this appendix we 1 ist Subroutine DETREND, which performs linear or quadratic detrending of a time series. The option is

$$
\begin{aligned}
& \mathrm{NP}=1 \text { - perform linear detrend } \\
& \mathrm{NP}=2 \text { - perform quadratic detrend. }
\end{aligned}
$$

Below the subroutine a calling program is 1 isted that submits a vector of 16 values to the subroutine.

$\mathrm{CCCC}$

$$
\text { SUBROUTINE DETREND ( } X, N X, A, B, N P)
$$

$C$ This subroutine accepts a vector, $X$ and performs either a first or second order detrending. Specifically

$N P=1$ - perform 1st order (1 inear) detrend

$N P=2$ - perform 2 nd order (quadratic or parabolic) detrend.

The $A(I)$ and $B(I)$ coefficients need not concern the user who is interested in the final product of the subroutine, only. This is an altered $x$ with either the best fitting linear polynomial removed or the best fitting quadratic polynomial removed, according to the value of NP. The mean The mean value is also removed, even if NP is zero.

The $A(I)$ are coefficients of

$$
P(X)=a(0) P[0](X)+a(1) P[1](X)+a(2) P[2](X)
$$

as shown in Equation (8) on page 131 of Wylie, "Advanced Engineering Mathematics, 3rd edition. $A(1)$ is $a(0) ; A(22)$ is $a(1)$, and $A(3)$ is $a(2)$. One may notice that at label 70 , where the detrending is actually performed, the coefficients of $X$ and $X^{\star * 2}$ are not $A(I)$ but are $B(I)$. The reason for this can be seen at the bottom of pager 130 in Wylie. $P[1](X)$ and $P[2](X)$ both include more than one degree of $X$. Therefore there is a more compact summation of these polynomials, and the $B(I)$ are the coefficients of this summation.

$\operatorname{cccC}$

DIMENSION $X(1), A(1), B(1)$

IF (NP.EQ.0)GO TO 80

$\mathrm{FN}=\mathrm{NX}-1$

$\mathrm{D}=\mathrm{FN}$ * $(\mathrm{FN}-1.0)$

DO $20 \mathrm{I}=1,3$

$A(I)=0.0$

$20 B(I)=0.0$

GO TO $(30,40)$, NP

$30 \quad 0035 \quad I=1, N X$

$F I=I-1$

$A(1)=A(1)+X(I)$ 
$35 A(2)=A(2)+X(1) \pm\left(1 \cdot 0-2 \cdot 0^{\star} F I / F N\right)$

$A(1)=A(1) /(F N+1.0)$

$A(2)=A(2) \star 3.0 \star F N /((F N+1.0) \star(F N+2.0))$

GO TO 60

40 DO $45 \quad 1=1$, NX

$F I=I-1$

$A(1)=A(1)+X(I)$

$A(2)=A(2)+X(I) \star(1 \cdot 0-2 \cdot 0 \star F 1 / F N)$

$45 A(3)=A(3)+X(1) *(1.0-6.0 * F I / F N+6.0 * F I *(F I-1.0) / D)$

$A(1)=A(1) /(F N+1.0)$

$A(2)=A(2) * 3.0 * F N /((F N+1.0) *(F N+2.0))$

$A(3)=A(3) * 5.0 * F N \star(F N-1.0) /((F N+1.0) *(F N+2.0) *(F N+3.0))$

$60 B(1)=A(1)+A(2)+A(3)$

$B(2)=A(2) *(-2.0 / F N)+A(3) *(-6.0 / F N-6.0 / D)$

$65 B(3)=A(3) * 6.0 / D$

DO $70 \mathrm{I}=1, \mathrm{NX}$

$\mathrm{FI}=\mathrm{I}-1$

$70 X(I)=X(I)-B(1)-B(2) * F I-B(3) * F I * F I$

GO TO 90

80 SUM $=0.0$

DO $83 \mathrm{I}=1$, NX

83 SUM $=S U M+X(I)$

SUM $=$ SUM $/$ FLOAT (NX)

DO $85 \mathrm{I}=1, \mathrm{NX}$

$85 X(I)=X(I)-S U M$

90 RETURN

END

C

PROGRAM DEMAIN

$\operatorname{CCCC}$

C This program provides hypothetical data and a call to a detrending

C subroutine. First linear detrending is performed, then after the

C original data are resupplied, quadratic detrending is performed.

C In each case the orthogonal detrending coefficients are printed out,

C as well as the "final" coefficients derived from them.

$\mathrm{CCCC}$

PARAMETER NDT $=16$

DIMENSION X(NDT), XSAVE(NDT), $A(3), B(3)$

DATA $(X(I), I=1, N D T) / 5.0,4.8,4.7,5.1,5.4,5.9,6.0,5.8$,

$\star 5.9,6.2,6.5,6.8,6.9,6.6,7.0,7.1 /$

DO 1 I $=1$, NDT

$1 \mathrm{XSAVE}(I)=X(1)$

WR1TE $(7,1001)(X(I), I=1$, NDT)

1001 FORMAT(1H , 'ORIGINAL DATA'/ $((1 \mathrm{H}, 8 \mathrm{F9} .2)))$

CALL DETREND $(X, N D T, A, B, 1)$

$\operatorname{WRITE}(7,2101)(A(I), 1=1,2)$

2101 FORMAT(1HO, 'ORTHOGONAL DETRENDING COEFFICIENTS FOR LINEAR

* DETREND'/((1H,2F9.3) )) 
$\operatorname{WRITE}(7,3101) \quad(B(I), I=1,2)$

3101 FORMAT(1HO, 'FINAL DETRENDING COEFFICIENTS FOR LINEAR DETREND'

*/((1H ,2F9.3)))

WRITE $(7,4501) \quad(X(I), I=1$, NDT $)$

4501 FORMAT(1H0, 'LINEARLY DETRENDED DATA'/((1H,8F9.2)))

DO $6 I=1, N D T$

$6 X(I)=X S A V E(I)$

CALL DETREND $(X, N D T, A, B, 2)$

WRITE $(7,6001)(A(I), I=1,3)$

6001 FORMAT (IHO, 'ORTHOGONAL DETRENDING COEFFICIENTS FOR QUADRATIC

^ DETREND'/((1H ,8F9.3)))

WRITE $(7,7101) \quad(B(I), I=1,3)$

7101 FORMAT (' 1 HO, ' FINAL DETRENDING COEFFICIENTS FOR QUADRATIC DETREND'

$\star /((1 \mathrm{H}, 8 \mathrm{F9} .3)))$

WRITE $(7,8101)(X(1), I=1$, NDT $)$

8101 FORMAT (IHO, 'QUADRATICALLY DETRENDED DATA' $/((1 \mathrm{H}, 8 \mathrm{F9} .2)))$

STOP

END

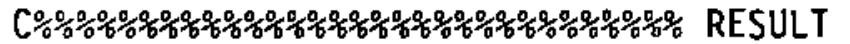

ORIGINAL DATA

$\begin{array}{llllllll}5.00 & 4.80 & 4.70 & 5.10 & 5.40 & 5.90 & 6.00 & 5.80 \\ 5.90 & 6.20 & 6.50 & 6.80 & 6.90 & 6.60 & 7.00 & 7.10\end{array}$

ORTHOGONAL DETRENDING COEFFICIENTS FOR LINEAR DETRENO

$5.981-1.221$

FINAL DETRENDING COEFFICIENTS FOR LINEAR DETREND

$4.760 \quad 0.163$

LINEARLY DETRENDED DATA

$\begin{array}{rrrrrrrr}0.24 & -0.12 & -0.39 & -0.15 & -0.01 & 0.33 & 0.26 & -0.10 \\ -0.16 & -0.03 & 0.11 & 0.25 & 0.19 & -0.28 & -0.04 & -0.10\end{array}$

ORTHOGONAL OETRENDING COEFFICIENTS FOR QUADRATIC DETREND

$5.981-1.221-0.075$

FINAL DETRENDING COEFFICIENTS FOR QUADRATIC DETREND

$\begin{array}{lll}4.685 & 0.195 & -0.002\end{array}$

QUADRATICALLY DETRENDED DATA

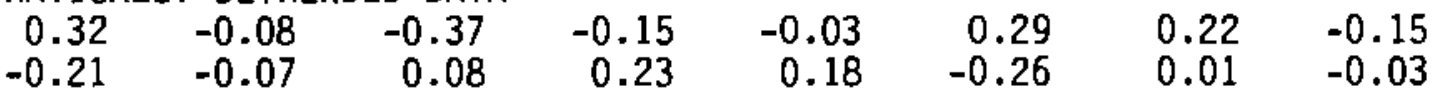


. 
APPENDIX E

DEFINITION OF AUTOCORRELATION FUNCTION 
APPENDIX E

\section{DEFINITION OF AUTOCORRELATION FUNCTION}

Assume a time series $(x(t), t=0, T)$ possesses second-order stationarity, and has a mean value of zero. Then we can define the autocorrelation of the process at a lag value, $t=\tau$, as

$$
R(\tau)=\frac{1}{\sigma_{x}^{2}} \lim _{T \rightarrow \infty}\left[\frac{1}{T} \int_{0}^{T} x(t) x(t+\tau) d t\right]
$$

where $\sigma_{X}{ }^{2}$ is the variance of $X$, and where $\tau$ remains limited.

From this definition we deduce that $R(0)=1.0$. Because the process possesses second-order stationarity, $R(\tau)$ approaches a limit of zero for sufficiently large $\tau$, such that the following integral exists,

$$
\text { Integral time scale }=\int_{0}^{\infty} R(\tau) d(\tau) \text {. }
$$

Then, by virtue of Taylor's hypothesis,

$$
\text { Integral length scale }=U \text { *Integral time scale, }
$$

where $U$ is the mean wind speed. 



\section{APPENDIX F}

REVISED KAIMAL SPECTRUM FOR WIND ENERGY APPLICATIONS 


\section{REVISED KAIMAL SPECTRUM FOR WIND ENERGY APPLICATIONS}

We have show that the published Kaimal spectrum integrates to a value of $4.7 u_{\star} 2$, while the general consensus is that the $\sigma_{U}^{2}$ is about $5.8 u_{\star}{ }^{2}$. We have also shown that $\sigma_{\mathrm{u}}{ }^{2}$ for time series at wind speeds that are operational for wind turbines is about 1.3 times $\sigma_{\mathrm{U}}{ }^{2}$ for neutral stability, when very stable cases are excluded. Therefore, we propose modification of the Kaimal spectrum that will bring $\sigma_{u}{ }^{2}$ up to the expected neutral value or bring $\sigma_{u}{ }^{2}$ up to greater values including $1.3 \sigma_{\mathrm{u}}{ }^{2}$, neutral.

The plan calls for leaving the right side of the spectrum fixed and raising the peak and the left side sufficiently to increase $\sigma_{u}{ }^{2}$ to prescribed levels. We do this because the right side of the spectrum may be prescribed with more confidence than the left side, and because the Hojstrup model for the unstable $u$ spectrum prescribes the same right side for the unstable case as for the neutral case.

The Kaimal u spectrum may be written

$$
\frac{n S_{u}(n)}{u_{\star}{ }^{2}}=\frac{A\left(f / f_{\max }\right)}{\left(1+1.5 f / f_{\max }\right)^{5 / 3}} .
$$

This is a better form because the value on the left maximizes when $f=f_{\max }$. Written thus, Equation (3.5) becomes

$$
\frac{n S_{u}(n)}{u_{\star}{ }^{2}}=\frac{4.773\left(\frac{f}{0.04545}\right)}{\left[1+1.5\left(\frac{f}{0.04545}\right)\right]^{5 / 3}} .
$$

Thus, $A=4.773$ and $f_{\max }=0.04545$. (More exactly, $A=105 / 22$ and $f_{\max }=$ 1/22.) We wish to manipulate $A$ and $f_{\max }$ so that the right side of the spectrum 
is fixed, but so that the left side encloses increased variance. It is easily shown that this can be done whenever

$$
\operatorname{Ln} A=-2 / 3 \operatorname{Ln} f_{\max }-0.498
$$

By running a computer program with a number of "trial-and-error" values of $f_{\max }$, we obtain the following suggested values for $A$ and $f_{\max }$ for Equation (F.1).

\begin{tabular}{|c|c|c|c|}
\hline Variance & $\sigma_{u^{2}}^{2 / u_{t}}{ }^{2}$ & A & $f_{u}$ \\
\hline Original & 4.5 & 4.8 & 0.046 \\
\hline Neutral expectation & 5.7 & 6.0 & 0.032 \\
\hline 1.1 Neutral expectation & 6.3 & 6.8 & 0.027 \\
\hline 1.2 Neutral expectation & 6.8 & 7.3 & 0.024 \\
\hline 1.3 Neutral expectation & 7.3 & 8.0 & 0.021 \\
\hline
\end{tabular}

The last version is the one that we recommend, in accordance with analysis of Clayton and AFCRL data reported above. However, the other versions are given for the user who may wish to use independent judgment on this matter. These spectra are plotted in Figure F.1.

Note that although this treatment adjusts the variances obtained by integrating the spectrum, the length scale that may be derived from the adjusted spectrum is still a linear function of height. 
.

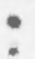

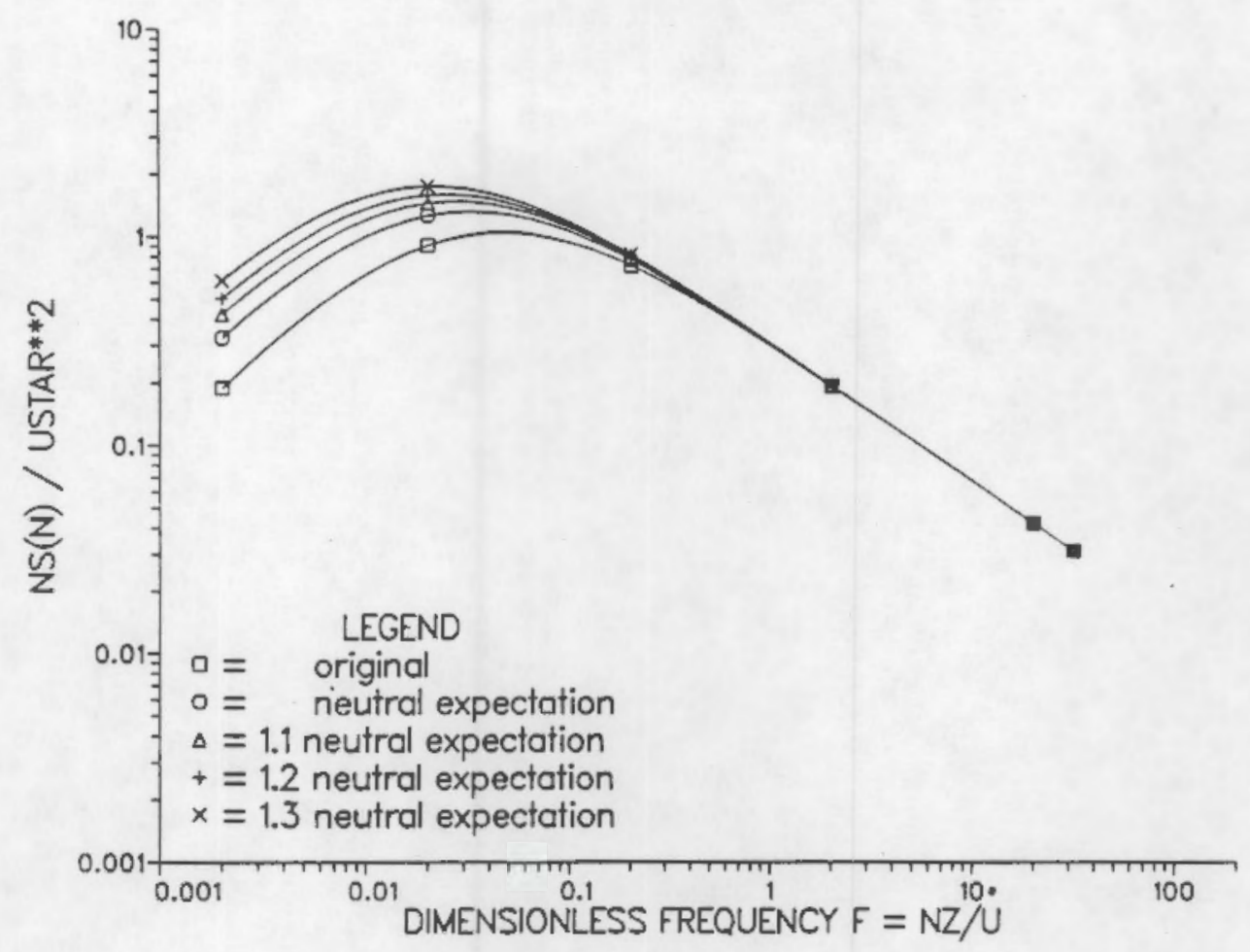

FIGURE F.1. Original and Four Revisions of Kaimal Neutral u Spectrum 



\section{DISTRIBUTION}

No. of

Copies

$\underline{\text { OFFSITE }}$

C. I. Aspliden

Battelle, Pacific Northwest Laboratories

370 L'Enfant Promenade, SW Washington, DC 20024-2115

J. Cadogan

U.S. Department of Energy

Wind/Ocean Technologies Division

1000 Independence Avenue

Forrestal Building, Room $5 F 064$

Washington, DC 20585

G. P. Tennyson

U.S. Department of Energy

ATbuquerque Operations office

P.0. Box 5400

Albuquerque, NM 87110

10 DOE/Office of Scientific and Technical Information

S. M. Chan

Systems Control, Inc.

1801 Page Mill Road

P.0. Box 10025

Palo Alto, CA 94303

R. L. George

TERRA Sciences, Inc.

7555 W. 10th Avenue

Lakewood, CO 80214

R. H. Kirchhoff

Department of Mechanical

Engineering

University of Massachusetts

Amherst, MA 01003

P. Klimas

Sandia National Laboratories

Division 6225

Albuquerque, NM 87185
No. of

Copies

P. M. Moretti

Oklahoma State University

Mechanical and Aerospace

Engineering

Engineering North 218

Stillwater, OK 74074

D. C. Reda

Sandia National Laboratories

Division 6225

Albuquerque, NM 87185

R. B. Schlueter

Department of Electrical

Engineering

Michigan State University

East Lansing, MI 48824

D. Spera

NASA/Lewis Research Center

21000 Brookpark Road

Cleveland, $\mathrm{OH} \quad 44135$

J. P. Sullivan

Aeronautics \& Astronautics

Grissom Hall

Purdue University

W. Lafayette, IN 47907

R. M. Sundar

Embry-Riddle Aeronautical

University

3200 N. Willow Creek Road

Prescott, AZ 86301

R. W. Thresher

Solar Energy Research Institute 1617 Cole Boulevard

Golden, C0 80401

V. A. Vachon

P.0. Box 149

Manchester, MA 01944 
No. of

Copies

P. Veers

2700 Del Medio Court $\$ 304$

Mountain View, CA 94040

S. N. Walker

Department of Mechanical

Engineering

Oregon State University

Corvallis, OR 97331

\section{ONSITE}

DOE Richland Operations Office

J. J. Sutey/D. R. Segna
No. of

Copies

27 Pacific Northwest Laboratory

J. C. Barnard

J. R. Connell

C. E. Elderkin

D. L. Elliott

J. W. Falco

M. J. Graham

J. M. Hales

P. C. Hays

R. A. Keefe (7)

V. R. Morris

E. L. Owczarski

D. C. Powell

J. A. Stottlemyre

L. L. Wendell

R. E. Wildung

Publishing Coordination

Technical Report Files (5) 